\title{
Analysis of the regional pattern of sea level change due to ocean dynamics and density change for 1993-2099 in observations and CMIP5 AOGCMs
}

\author{
Roberto A. F. Bilbao • Jonathan M. Gregory • \\ Nathaelle Bouttes
}

Received: 8 October 2014 / Accepted: 24 January 2015 / Published online: 24 February 2015

(c) The Author(s) 2015. This article is published with open access at Springerlink.com

\begin{abstract}
Predictions of twenty-first century sea level change show strong regional variation. Regional sea level change observed by satellite altimetry since 1993 is also not spatially homogenous. By comparison with historical and pre-industrial control simulations using the atmosphere-ocean general circulation models (AOGCMs) of the CMIP5 project, we conclude that the observed pattern is generally dominated by unforced (internal generated) variability, although some regions, especially in the Southern Ocean, may already show an externally forced response. Simulated unforced variability cannot explain the observed trends in the tropical Pacific, but we suggest that this is due to inadequate simulation of variability by CMIP5 AOGCMs, rather than evidence of anthropogenic change. We apply the method of pattern scaling to projections of sea level change and show that it gives accurate estimates of future local sea level change in response to anthropogenic forcing as simulated by the AOGCMs under RCP scenarios, implying that the pattern will remain stable in future decades. We note, however, that use of a single integration to evaluate the performance of the pattern-scaling method tends to exaggerate its accuracy. We find that ocean volume mean temperature is generally a better predictor than global mean surface temperature of the magnitude of
\end{abstract}

\footnotetext{
R. A. F. Bilbao $(\square)$

Meteorology Department, University of Reading, Reading RG6 6BB, UK

e-mail: r.a.fernandezbilbao@pgr.reading.ac.uk

J. M. Gregory $\cdot$ N. Bouttes

NCAS-Climate, Meteorology Department, University

of Reading, Reading RG6 6BB, UK

J. M. Gregory

Met Office Hadley Centre, Exeter EX1 3PB, UK
}

sea level change, and that the pattern is very similar under the different RCPs for a given model. We determine that the forced signal will be detectable above the noise of unforced internal variability within the next decade globally and may already be detectable in the tropical Atlantic.

Keywords Regional sea level change · Pattern scaling . Times of emergence

\section{Introduction}

Tide-gauge observations show that global mean sea level has risen by about $0.19 \mathrm{~m}$ since 1901 (Church and White 2011; Ray and Douglas 2011; Rhein et al. 2013). Global mean sea level rise results principally from thermal expansion of sea water and from increase in the mass of the oceans due to reduction of the mass of land ice (Church et al. 2011, 2013; Gregory et al. 2013). Projections based on results from Atmosphere-Ocean General Circulation Models (AOGCMs) indicate that global mean sea level will continue to rise throughout the twenty-first century (Meehl et al. 2007; Church et al. 2013). According to the Fifth Assessment Report of the Intergovernmental Panel on Climate Change, global mean sea level rise by 2100 with respect to the 1996-2005 mean will likely amount to between 0.3 and $1.0 \mathrm{~m}$, depending on scenario; in all scenarios, thermal expansion is the largest contribution, and accounts for about 30-55 \% (Church et al. 2013).

Recent sea level change has strong regional variations, as is revealed by the continuous near-global satellite altimetry observations by the TOPEX/Poseidon and JASON missions since 1993 (Cazenave and Nerem 2004; Meyssignac et al. 2012). Predicted future sea level rise is likewise not spatially uniform, but models show disagreement in 
its geographical pattern for the next century (Meehl et al. 2007; Yin 2012; Bouttes et al. 2012; Church et al. 2013; Slangen et al. 2012, 2014).

The geographical pattern of sea level change (with respect to the geoid, which is the surface of constant geopotential that would describe sea level if the ocean were at rest) results from the superposition of 'fingerprints' resulting from different processes with various time-scales (Mitrovica et al. 2001; Bamber and Riva 2010; Kopp et al. 2010; Tamisiea 2011; Slangen et al. 2012, 2014; Perrette et al. 2013). Local sea level change is due to changes in density of the ocean from changes of temperature and salinity (thermosteric and halosteric sea level change, respectively), changes in the ocean circulation (which are strongly related to changes in density by ocean dynamics), water and ice redistribution between the land and ocean (leading to changes in the Earth's gravitational field and rotation and to flexure of the lithosphere), and changes in atmospheric pressure (Mitrovica et al. 2001; Tamisiea 2011; Bamber and Riva 2010; Kopp et al. 2010; Perrette et al. 2013; Lyu et al. 2014).

The physical processes which determine global-mean sea level rise and regional sea level change are not identi$\mathrm{cal}$, although they are related. We therefore treat them separately, as is done in most models and model-based analyses (Church et al. 2013). Our focus throughout this paper is on regional sea level change with respect to global mean sea level. Because sea level rise can threaten coastal populations (Nicholls et al. 2011), the most relevant information to anticipate future impacts and needs for adaptation is prediction of regional sea level change with respect to its present level, which is the sum $h+\eta$ of global mean sea level rise $h$, and the difference of regional sea level change $\eta$ from global mean sea level rise. The spread among models in projections of $\eta$ is substantial compared with $h$ (Church et al. 2013). This is a serious drawback for predicting regional sea level change. Hence it is important to reduce the uncertainty in $\eta$.

One way to make progress is by enquiring whether observed regional sea level change is a consequence of climate change forced by anthropogenic or natural (volcanic and solar) influences, or whether it is due to unforced variability generated spontaneously within the climate system, associated with phenomena such as the El Niño Southern Oscillation (ENSO) or the Inter-decadal Pacific Oscillation (IPO), i.e. whether the forced climate change signal can be 'detected' in the sea level change observations. If it can, we would have greater confidence in projections made using a model which simulates forced patterns of sea level change in agreement with observations.

Much work has been done to detect the signal of forced climate change in many other areas of the climate system relevant to sea level change, especially ocean warming
(Bindoff et al. 2007; Palmer et al. 2007). Yet little has been done in detection and attribution of sea level change itself, for two reasons. First, it has been problematic to account for observed global mean sea level change over the past century in terms of known contributions; this is a pre-requisite for confidence in physical understanding. Therefore many recent studies have focused on closing the global sea level budget, and progress has been made (Church et al. 2011; Gregory et al. 2013). Second, the patterns of sea level rise before the altimeter period are known from tide gauge records, which are relatively few in number and only along coastlines, whereas for other climate variables such as surface air temperature, precipitation and ocean interior, observational records with widespread coverage extending back several decades are available. The short record of regional sea level change imposes a limit on the statistical significance of detection and attribution.

In this work we use AOGCM simulations from the Coupled Model Intercomparison Project Phase 5 (CMIP5) to study the pattern of sea level change resulting from density and circulation changes in the ocean, which are in turn driven by surface fluxes of momentum, heat and fresh water (Lowe and Gregory 2006; Pardaens et al. 2011; Bouttes and Gregory 2014). This contribution to the pattern is currently dominant, though in the latter part of the twenty-first century it is likely that the fingerprint of land ice change will become more important and perhaps dominant, depending on the magnitude of land ice loss (Bamber and Riva 2010; Kopp et al. 2010; Perrette et al. 2013; Church et al. 2013).

We address three questions related to the pattern of sea level change due to forcing of the climate system. First, is the forced pattern detectable in observations to date? Second, is sea level change in future decades expected to have a constant pattern (with an increasing amplitude)? If the pattern is constant, observed change can be used to refine the estimates of future change, making this a question of practical significance. Third, when will local sea level change be detectable above the background of unforced local variability? This is referred to as the time of emergence (Hawkins and Sutton 2012; Lyu et al. 2014), and is the relevant timescale for implementing local adaptation measures.

To address the latter two questions we apply the method of pattern scaling to sea level change (Santer et al. 1990; Mitchell et al. 1999; Mitchell 2003; Collins et al. 2013; Perrette et al. 2013). We investigate a variety of predictors of sea level change and analyse the accuracy of the method. The main advantage of this method is that it provides a way to estimate the pattern of forced sea level change with negligible unforced internal variability. An application for this method is that it can be used to estimate local sea level change for model scenarios where an AOGCM experiment is not available, provided that there are means to estimate the predictor variable and the pattern is independent of scenario. 


\section{The pattern of sea level change since 1993}

Observed (TOPEX/Poseidon and Jason) sea level change trends from 1993-2012, from linear regression of local sea level change against time (Fig. 1a), show several characteristic features such as an East-West dipole in the Pacific, a meridional dipole in the North Atlantic, and enhanced sea level rise around $45^{\circ} \mathrm{N}$ in the Southern Ocean. Understanding whether these features are the result of anthropogenic climate change or unforced internal variability is of major importance for understanding ocean dynamics and future projections of sea level change.

The East-West dipole in the Pacific Ocean is the most prominent feature of the observed sea level trends and has been associated with the dominating negative phase of the IPO in recent decades (Meehl and Hu 2013) and trade wind intensification (Carton et al. 2005; Timmermann et al. 2011; Merrifield 2013; Merrifield et al. 2011). Several studies have shown that forcing climate models with observed winds results in the observed pattern (Merrield and Maltrud 2011; McGregor and Sen Gupta 2012; England et al. 2014; Griffies et al. 2014). Negative wind stress curl anomalies in the Western Tropical Pacific lead to downwelling of warm waters, deepening of the thermocline and thermosteric sea level rise, while the opposite occurs in the Eastern Tropical Pacific (Griffies et al. 2014).

Meyssignac et al. (2012) considered whether the observed sea level trend pattern in the tropical Pacific ocean is an externally forced response or unforced internally generated variability by comparing satellite altimetry observations (1993-2009) with past sea level reconstructions and with CMIP3 pre-industrial controls and twentieth century runs. Their study concludes that the period 1993-2009 is too short to detect an externally forced signal and that the pattern is consistent with unforced internal variability as exhibited by reconstructions of historical sea level change and by pre-industrial simulations using AOCGMs of the Coupled Model Intercomparison Project Phase 3 (CMIP3).

The North Atlantic meridional dipole is characterised by increased sea level around Greenland and decreased sea level in the Gulf Stream. A qualitatively similar feature is predicted by most AOGCMs for future decades (Bryan 1996; Lowe and Gregory 2006; Pardaens et al. 2011; Bouttes et al. 2013a; Church et al. 2013), and is associated with changes in heat flux and the Atlantic meridional overturning circulation (AMOC), due to changes in surface buoyancy fluxes (freshwater and heat) (Yin 2012; Bouttes et al. 2013a).

Observed sea level change in the Southern Ocean is characterised by a band of rising sea level approximately at $45^{\circ} \mathrm{S}$, and steady or falling sea level further south. Understanding this feature of sea level change is of major importance as it is the dominant and most robust feature of
AOGCM projections for the twenty-first century (Meehl et al. 2007; Pardaens et al. 2011; Bouttes et al. 2012; Yin 2012; Church et al. 2013). It is probably associated with changes in westerly winds in the Southern Ocean (Thompson et al. 2000), and hence in the wind driven overturning circulation and the meridional sea level gradient associated with the Antarctic Circumpolar Current (Frankcombe et al. 2013).

Our first question is whether a forced pattern of sea level change is detectable in observations to date. This question has two aspects. First, are observed sea level trends consistent with unforced variability of the climate system? Second, are they consistent with forced climate change?

To address the first aspect, we compare the trends in annual mean sea level observed by satellite altimetry (from the TOPEX/Poseidon and Jason missions) for the period 1993-2012 with trends in annual mean sea level for periods of the same length (20 years) simulated in pre-industrial control simulations of 21 CMIP5 models (see Table 1). Trends in the control simulations can be due only to variability generated internally by the simulated climate system, because all forcing agents (anthropogenic and natural) are held constant.

Sea level change from satellite altimetry includes all the processes that lead to geographical changes in sea level, including the effect on the geoid of ongoing change in land ice, and Glacial Isostatic Adjustment (GIA) in response to land-ice changes over millennia (Peltier 2004; Church et al. 2013). For the satellite altimetry period, the former is negligible (Kopp et al. 2010), however the GIA contribution is significant in some regions. Since we are interested in the sea level change as a result of ocean circulation and density change only, we correct the observed sea level change by subtracting sea level change pattern resulting from the geoid change due to GIA estimated by Peltier (2004). Applying the GIA correction varies the observed pattern of sea level change very slightly.

Since the gridded dataset of satellite altimeter observations has a significantly higher resolution than most CMIP5 models and shows small-scale features not simulated in models, the data from both observations and models were first averaged onto a common $5^{\circ} \times 5^{\circ}$ grid.

Because the deep ocean requires millennia to reach a steady state, there are typically non-zero long-term trends in the control experiment of an AOGCM, despite the constant boundary conditions. These drifts are small for the surface climate in CMIP5 pre-industrial control simulations, but substantial for quantities affected by the state of the deep ocean, including local and global mean sea level (Sen Gupta et al. 2013). Therefore we remove the drift in local sea level in the CMIP5 pre-industrial control runs, caused by insufficient spin-up, by the method described in "Appendix". 
We computed longitude-latitude fields of trends from the observational dataset and from each drift-corrected 20-year model control segments by linear regression against time, and for each model we computed a distribution of trends at each gridbox from the set of segments. To maximise the amount of information regarding variability on all time periods the 20 years segments of control begin in consecutive years and thus overlap. From the trend distributions for each model, we calculate the 2.5 and 97.5 percentiles at each gridbox. If the observational trend at a gridbox lies outside these limits, we conclude that it differs significantly from unforced variability (at the $5 \%$ level), according to the model used.

Figure 1a indicates the regions where the trend is significant in at least $2 / 3$ of CMIP5 pre-industrial control simulations analysed. Regions where the observed trends are significant are the tropical Pacific, the Equatorial Atlantic, and parts of the Southern Pacific, Indian Ocean and Southern Ocean. Where the observed trend is not consistent with simulated unforced variability, we conclude either that the simulated unforced variability is unrealistically small i.e. larger unforced trends are generated in the real world than in the models, or that the observed trend has a forced contribution.

The tropical Pacific is of particular interest. Meyssignac et al. (2012) conclude that the observed trends in this region are consistent with the geographical patterns and power spectra of unforced variability in AOGCM pre-industrial control simulations. Our analysis, however, shows that the magnitude of the trends is significantly larger than, and therefore not consistent with, simulated unforced variability in AOGCMs. We reach a different conclusion from theirs because our focus is on the magnitude of trends rather than their spatiotemporal characteristics. However, we note that inconsistency with control variability does not mean that observed trends can be attributed to external forcing, which we consider next.

We determine whether the forced pattern of sea level change can be detected in observations by comparing with historical simulations of CMIP5 AOGCMs for 1993-2005 (Fig. 1b, c), which is the longest period possible (the CMIP5 projections under RCP scenarios begin in 2006). In a similar way to previously described, we calculate the linear trend patterns for sea level change observations and CMIP5 historical simulations by linearly regressing against time. Historical runs of CMIP5 AOGCMs show a range of spatial patterns of sea level trends for the period 1993-2005. Where the observed pattern of sea level change is dominated by unforced internal variability, we would not expect the CMIP5 historical experiments to simulate it. On the other hand, a forced response should be consistent in the models and should show agreement with observations. The CMIP5 multi-model ensemble mean shows that trends

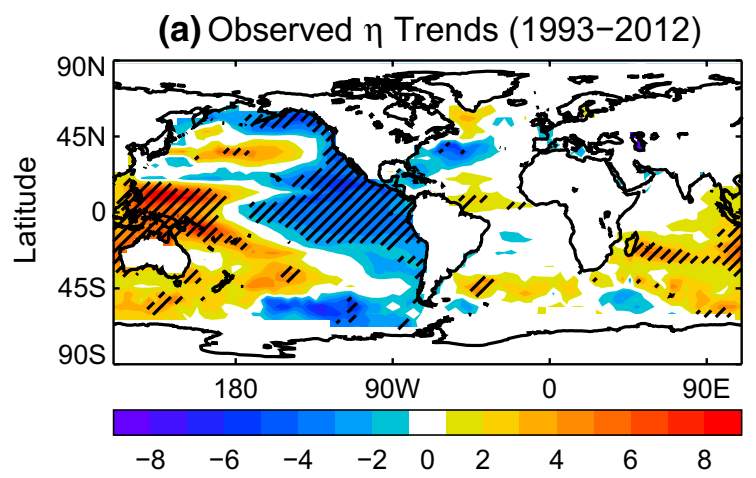

(b) Observed $\eta$ Trends (1993-2005)

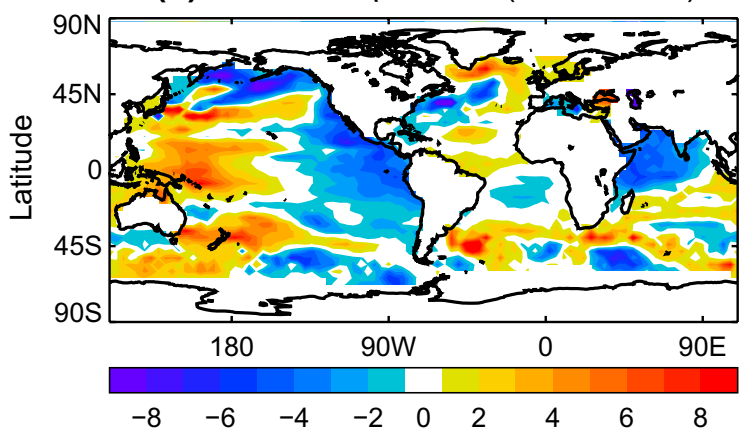

(c) CMIP5 Ensemble Mean $\eta$ Trends (1993-2005)

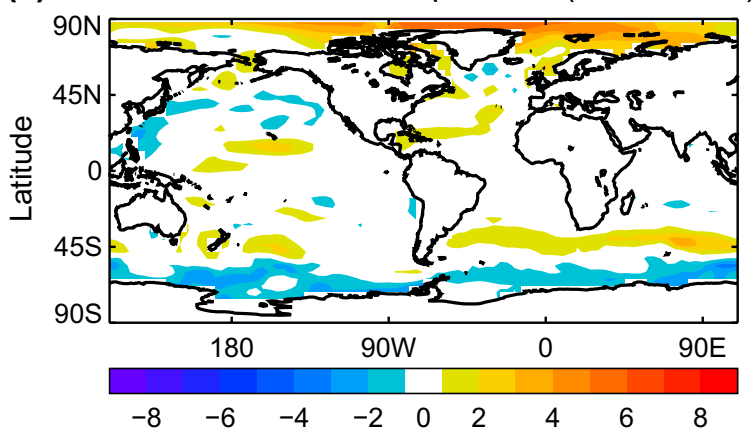

(d) CMIP5 Ensemble Std. Dev. $\eta$ Trends (1993-2005)

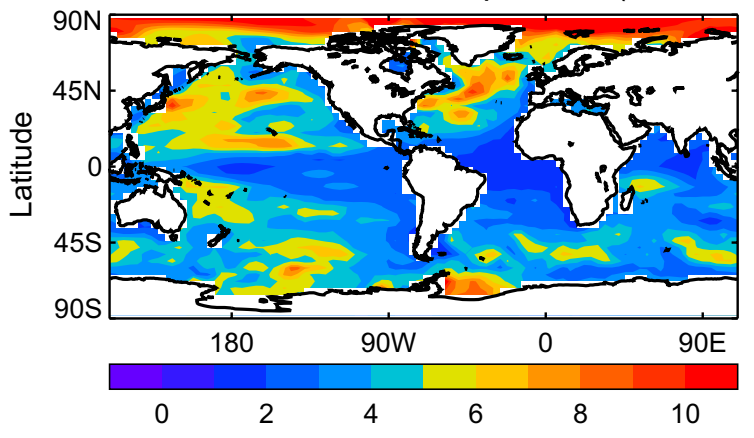

Fig. 1 a Observed sea level change trends (mm/year) from satellite altimetry between 1993-2012. The hatching indicates trends that are significant (at the $5 \%$ level) with respect to at least 2/3 of CMIP5 pre-industrial control simulations. b Observed sea level change trends (mm/year) from satellite altimetry (1993-2005). c Ensemble mean sea level trends (mm/year) from CMIP5 historical simulations between 1993-2005 and d CMIP5 ensemble spread (mm/year). All figures have been re-gridded by averaging on a $5^{\circ} \times 5^{\circ}$ grid 
Table 1 List of CMIP5 AOGCMs analysed in this work, with the number of ensemble members available and the percentage area where the last 20 years residuals and pre-industrial control 20 -year variability are significantly different ( $5 \%$ significance level)

\begin{tabular}{|c|c|c|c|c|c|c|c|}
\hline \multirow[t]{2}{*}{ Models } & \multirow{2}{*}{$\begin{array}{l}\text { Num. of } \\
\text { Ensemble } \\
\text { Members }\end{array}$} & \multicolumn{2}{|l|}{ RCP2.6 } & \multicolumn{2}{|l|}{$\mathrm{RCP} 4.5$} & \multicolumn{2}{|l|}{ RCP8.5 } \\
\hline & & $\begin{array}{l}\text { RCP2 } 2.6 \text { pattern } \\
(\%)\end{array}$ & $\begin{array}{l}\text { All-RCP pattern } \\
(\%)\end{array}$ & $\begin{array}{l}\text { RCP4.5 pattern } \\
(\%)\end{array}$ & $\begin{array}{l}\text { All-RCP pattern } \\
(\%)\end{array}$ & $\begin{array}{l}\text { RCP8.5 pattern } \\
(\%)\end{array}$ & $\begin{array}{l}\text { All-RCP pattern } \\
(\%)\end{array}$ \\
\hline ACCESS1-0 & 1 & - & - & 12 & - & 14 & - \\
\hline ACCESS1-3 & 1 & - & - & 7 & - & 14 & - \\
\hline CNRM-CM5 & 1 & 4 & 14 & 2 & 6 & 1 & 13 \\
\hline \multicolumn{8}{|l|}{ CSIRO-Mk3-6-0 } \\
\hline (method 1) & 10 & 12 & - & 5 & - & 6 & - \\
\hline (method 2) & & 35 & 34 & 33 & 34 & 32 & 65 \\
\hline \multicolumn{8}{|l|}{ CanESM2 } \\
\hline (method 1) & 5 & 8 & 34 & 10 & 27 & 6 & 29 \\
\hline (method 2) & & - & - & 5 & - & 9 & - \\
\hline GFDL-ESM2M & 1 & 8 & 34 & 10 & 27 & 6 & 29 \\
\hline HadGEM2-CC & 1 & - & - & 5 & - & 9 & - \\
\hline \multicolumn{8}{|l|}{ HadGEM2-ES } \\
\hline (method 1) & 4 & 8 & - & 5 & - & 5 & - \\
\hline (method 2) & & 27 & 27 & 28 & 42 & 30 & 63 \\
\hline IPSL-CM5A-LR & 1 & 23 & 53 & 6 & 16 & 5 & 33 \\
\hline IPSL-CM5A-MR & 1 & 4 & 28 & 5 & 16 & 7 & 31 \\
\hline MPI-ESM-LR & 1 & 3 & 41 & 4 & 10 & 3 & 23 \\
\hline MPI-ESM-MR & 1 & 13 & 40 & 3 & 13 & 3 & 25 \\
\hline MRI-CGCM3 & 1 & 7 & 17 & 3 & 15 & 7 & 25 \\
\hline NorESM1-M & 1 & 12 & 29 & 5 & 27 & 11 & 34 \\
\hline NorESM1-ME & 1 & 9 & 27 & 8 & 14 & 14 & 33 \\
\hline inmcm4 & 1 & - & - & 3 & - & 2 & - \\
\hline
\end{tabular}

average out in large parts of the world (Fig. 1c); this suggests that the observed sea level trends in those regions are dominated by internal variability.

The East-West dipole in the Pacific, which is the dominant feature of the observed trends, is not simulated in the CMIP5 historical experiments (1993-2005), except for one ensemble member of HadGEM2-ES and CanESM2, and does not appear in the multi-model mean. The observed pattern however is not unusual in climate model simulations; decades with a similar pattern have been associated with a hiatus in the rate of global warming (Meehl and Hu 2013). Yet the observed magnitude is outside the range of simulated unforced variability. We think it likely that the recent Pacific sea level trends are due to unforced variability, not external forcing, but that CMIP5 models are deficient in simulating the magnitude of unforced decadal variability in the tropical Pacific. This in turn is probably associated with an underestimation of the unforced variability in the trade winds (cf. England et al. 2014).

In the North Atlantic, there is a large spread of trends across the models (Fig. 1d). Most models simulate a meridional dipole, although with varying shape, indicating a common cause, presumably related to the heat flux and Atlantic Meridional Overturning Circulation (AMOC) (Katsman et al. 2008; Bouttes et al. 2012). In some models, and in the model mean, the sign of the dipole is reversed compared to observations, but this is unproblematic because the simulated and observed trends in this region are consistent with unforced decadal variability (Fig. 1a).

Almost all CMIP5 AOGCMs analysed (Table 1) simulate the Southern Ocean meridional dipole, with increased sea level change band at approximately $45^{\circ} \mathrm{S}$, although this feature also varies in shape, magnitude and location among the models. The agreement among historical simulations, and the fact that the observed trend significantly exceeds simulated unforced variability in some regions and models, suggest that the observed Southern Ocean dipole is a forced response. It is likely that this feature is of anthropogenic origin, because ozone depletion over Antarctica and increasing greenhouse gas concentration in the atmosphere could have caused the intensification and poleward shift of the westerly winds (Cai 2006; Fyfe et al. 2007). 


\section{Estimating the pattern of future sea level change}

In this section we analyse the forced pattern of sea level change in CMIP5 AOGCM projections relative to the global mean change, in order to address the second question: is the pattern constant in time? Following the method of pattern scaling (Santer et al. 1990; Mitchell et al. 1999; Mitchell 2003; Collins et al. 2013; Perrette et al. 2013), we assume that $\eta$ (sea level change relative to the control, with the global mean subtracted and drift removed following "Appendix") can be decomposed into a spatial pattern $P(\underline{x})$, which is a function only of location $\underline{x}$, and amplitude $S(t)$, which is a function only of time $t$, and unforced internally generated variability $(\varepsilon)$ regarded as random noise with a stationary Gaussian distribution,

$\eta(\underline{x}, t)=P(\underline{x}) S(t)+\varepsilon(\underline{x}, t)$

In previous studies, it has been shown that this assumption is reasonable for other variables of the climate system; in particular, that local surface air temperature change scales well with global-mean surface air temperature change (Hawkins and Sutton 2012; Collins et al. 2013). To obtain accurate results from the method of pattern scaling for sea level change we have to determine the best choice for the sea level predictor $S$, which is a global-mean variable indicating the magnitude of local sea level change relative to global mean sea level change.

Once $S$ is chosen, the sea level change pattern $P(x)$ is calculated as the gradient of the linear regression of $\eta(\underline{x}, t)$ against $S(t)$ at each location $\underline{x}$. In the regression, we do not allow for a non-zero intercept (that is, we force $\eta=0$ when $S=0$ ) because the scaling method (as shown by Eq. 1) implies that there is no offset. When carrying out the regression, we express both $\eta$ and $S$ as differences from the time-mean of a reference period. The regression is done using ordinary least squares with $S$ as the independent variable, implying that all variations in $S$ predict variations in $\eta$, but in addition there are unpredictable variations in $\eta$, characterized by $\varepsilon$, which emerge as the residual from the regression.

We can then use pattern scaling to estimate the expected sea level change fields according to $\eta_{P S}(\underline{x}, t)=P(\underline{x}) S(t)$. This estimate has small or negligible unforced variability, because the pattern was determined from many years of data, and the predictor is a global variable.

\subsection{Spatial standard deviation as a time-dependent indicator of the magnitude of local sea level change}

Because the global mean is used as the predictor in pattern scaling studies of surface air temperature change, analogy might suggest the global-mean of $\eta$ as our predictor, but by construction $\eta$ has zero global mean and gives no information on the time evolution of sea level change. Therefore, we adopt the time-series of the areaweighted spatial variance of sea level change as a measure of the magnitude of local sea level change relative to the global mean, and use this information to determine what a suitable predictor might be on the basis of temporal correlations. Taking the area-weighted spatial variance of Eq. (1):

$\operatorname{var}[\eta(\underline{x}, t)]=\operatorname{var}[P(\underline{x}) S(t)]+\operatorname{var}[\varepsilon(\underline{x}, t)]$

since $\varepsilon$ is random noise and not correlated with $P$ or $S$. Rewriting Eq. (2):

$\sqrt{\mathrm{SD}[\eta(\underline{x}, t)]^{2}-\mathrm{SD}[\varepsilon(\underline{x}, t)]^{2}}=\mathrm{SD}[P(\underline{x})] S(t)$

where here SD is the area-weighted spatial standard deviation. The left-hand-side of Eq. (3) is proportional to $S(t)$ because $\operatorname{std}(P(x))$ is a constant. The unforced variability $\varepsilon$ at any time in the scenario experiment is an unknown part of $\eta$. We assume unforced variability to be independent of the state of the climate, and use the time-mean of the areaweighted interannual standard deviation of local sea level in the drift-subtracted (see "Appendix") pre-industrial control simulation as a time-independent estimate of $\operatorname{std}(\varepsilon)$. For this purpose, we use the entire length of the control run.

We calculate the left-hand side of Eq. (3) for annual means from the CMIP5 historical + RCP experiments shown in Table 1, which all branch from the control simulation. They have historical forcings from the mid-nineteenth century up to 2005 , then for 2006-2100 follow three representative concentration pathways (RCP): 2.6, 4.5 and 8.5 (Taylor et al. 2012). We consider sea level change relative to 1993-2012 i.e. the satellite observational period.

Subtracting $\varepsilon$ in quadrature from $\eta$ in Eq. (3) may result in the square root of a negative value when the unforced internal variability dominates. This happens until the $1980 \mathrm{~s}$ and therefore we consider the time-series starting from the year after the latest year in which $\mathrm{SD}[\varepsilon]>\mathrm{SD}[\eta]$. Since we are interested in estimating the forced pattern of sea level change, time-periods where internal variability dominates are not relevant.

With unforced variability subtracted, the historical + RCP simulations show that area-weighted spatial standard deviation of sea level change is flat up to approximately the year 2000, and then increases steadily until the end of the twenty-first century (blue lines in Fig. 2). Before subtracting the unforced variability, the spatial standard deviation is larger, and increases more slowly in the early decades of the century (red lines in Fig. 2). In some of the models and experiments the rate of increase decreases towards the end of the twenty-first century suggesting a stabilisation, especially under RCP2.6 (Fig. 2a). 
(a) Historical+RCP2.6

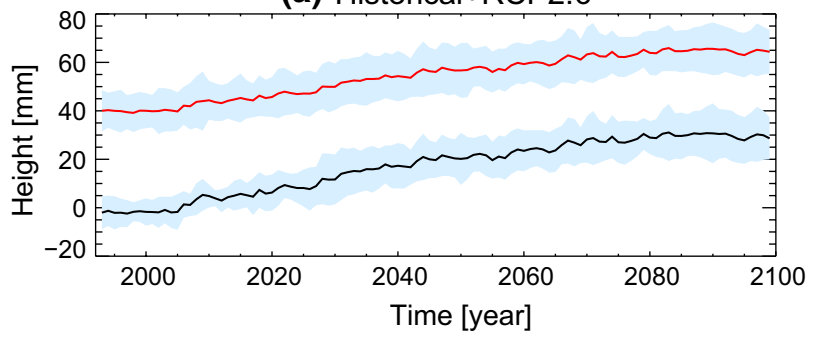

(b) Historical+RCP4.5

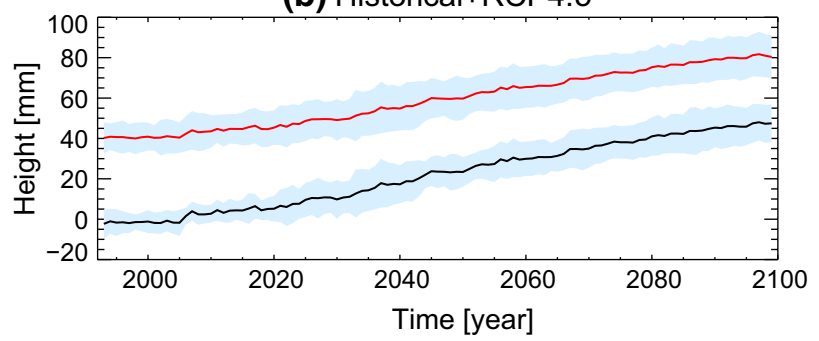

(c) Historical+RCP8.5

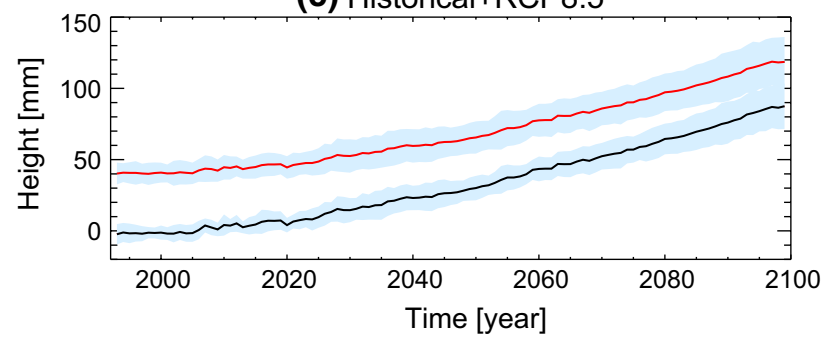

Fig. 2 CMIP5 ensemble mean area-weighted spatial standard deviation of sea level change $\eta$ (red lines) $[\mathrm{mm}]$ for (a) histori$\mathrm{cal}+\mathrm{RCP} 2.6$, b historical + RCP4.5 and $\mathbf{c}$ historical + RCP8.5. The forced component of $\eta$ (black lines) is calculated by subtracting the estimate of unforced internal variability $\varepsilon$ (from pre-industrial control simulations) in quadrature-see Eq. (3). For both lines the shading represents the CMIP5 ensemble spread as $\pm 1 \mathrm{SD}$. The time-series are relative to the 1993-2012 mean

\subsection{Choice of global variable to predict the magnitude of local sea level change}

The pattern of regional sea level change is affected by changes in temperature and salinity, which are themselves affected by changes in surface fluxes of momentum, heat and freshwater (Lowe and Gregory 2006; Bouttes and Gregory 2014). For pattern scaling to be satisfactory, we must assume that all of these changes scale together and are proportional to a single variable that represents the magnitude of all aspects of global climate change which affect sea level. Global mean surface air temperature (SAT) is commonly used for pattern scaling, and we also consider global mean sea surface temperature (SST) because climate change over the ocean might be a better predictor of regional sea level change. Sea level change does not depend only on surface climate change, because interior redistribution of heat affects the density gradients (Lowe and Gregory 2006). Temperature and salinity change penetrate to different depths in different regions (Pardaens et al. 2011). We therefore also consider as a possible predictor the ocean volume mean temperature integrated from the surface down to $300,700,2,000 \mathrm{~m}$ and the total depth (using the closest level to the nominal depth in each models to avoid vertical interpolation). Since density change depends on the thermal expansion coefficient, which is dependent on both temperature and pressure, and hence on the three-dimensional temperature field in the model simulation, we consider global mean thermal expansion as another predictor, evaluated to the same depths as volume mean temperature change.

Figure 3 shows these possible predictor time series for historical + RCP4.5. This scenario is shown as an example. Change in all quantities is expressed with respect to the time-mean of 1993-2012. Ocean volume mean temperature and global-mean thermosteric sea level averaged over different depths show differences in the time-series shapes. In particular, the time-series integrated over the first $300 \mathrm{~m}$ tend to stabilise towards the end of the twenty-first century, like surface temperature, whereas the time-series integrated over deeper layers do not, because deep-ocean temperature change is approximately a time-integral of surface temperature change (Bouttes et al. 2013b). Ocean volume mean temperature and global-mean thermosteric sea level timeseries for the same depth ranges are almost identical in shape (Fig. 3), as shown by Kuhlbrodt and Gregory (2012) for the full depth.

The global-mean SST and SAT time-series are characterised by larger unforced interannual variability. Averaging over deeper layers results in a gradual decrease in variability (Gregory 2000; Palmer et al. 2007; Winton et al. 2010). Similarly, the area-weighted spatial standard deviation of sea level shows high-frequency variability of similar (fractional) size to surface temperature.

To determine the best possible scaling factor we correlate the left-hand-side of Eq. (3) with the various possible predictors. A better predictor would have a higher correlation. Under historical + RCP4.5, all the global-mean predictors analysed, for all the models, show a high correlation with the left-hand-side of Eq. (3), ranging between 0.85 and 0.99 (Fig. 4). The correlations for the ocean volume mean temperature and global-mean thermosteric sea level are similar when averaged over the same depths, and generally have higher correlations than global mean SAT and global mean SST. The main differences between models relates to the depth to which ocean volume mean temperature and global-mean thermosteric sea level are averaged.

Since the correlations are affected by the high-frequency variability in the area-weighted spatial standard deviation, SAT and SST time-series, they were reevaluated after 
(a) SAT

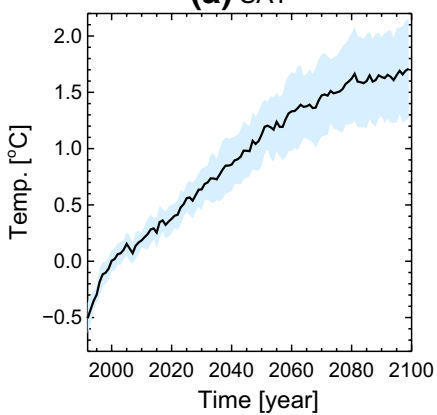

(e) OVMT $0-2000 \mathrm{~m}$
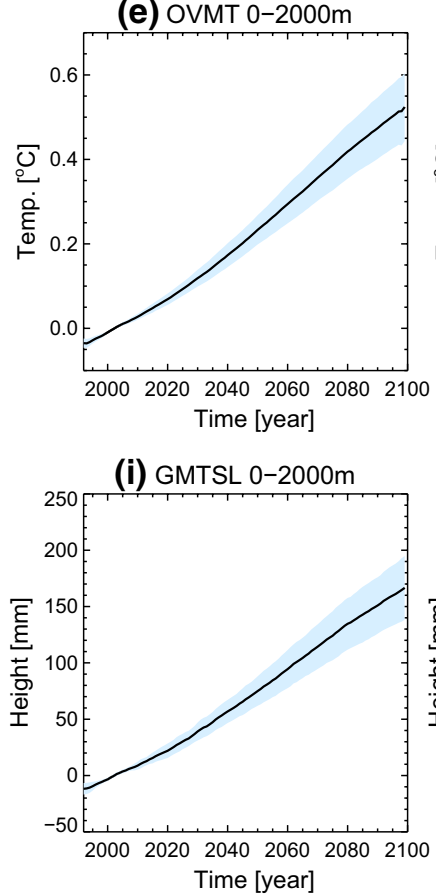

(b) SST

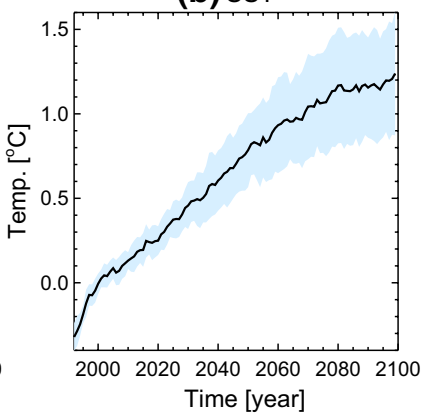

(f) OVMT Total
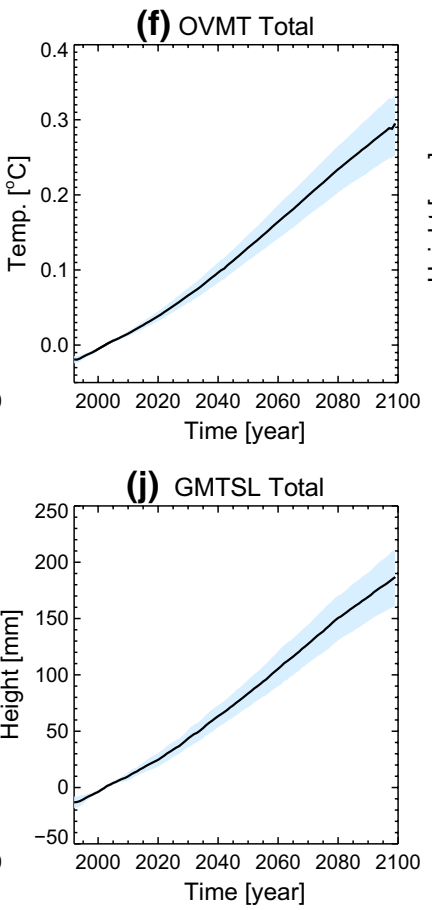

(c) OVMT 0-300m

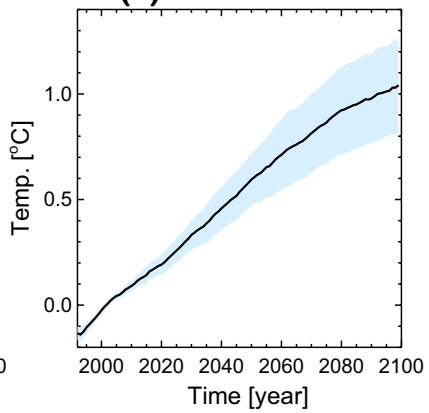

(g) GMTSL $0-300 \mathrm{~m}$

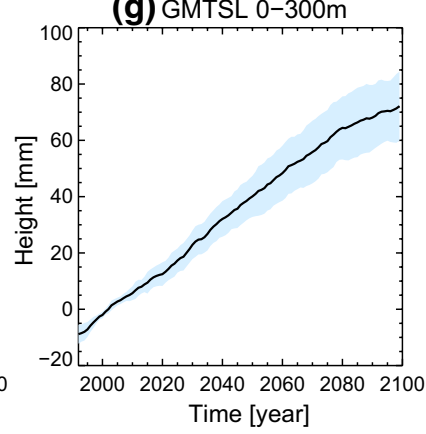

(d) OVMT 0-700m

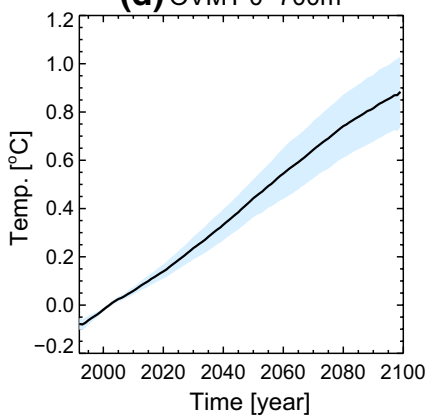

(h) GMTSL 0-700m

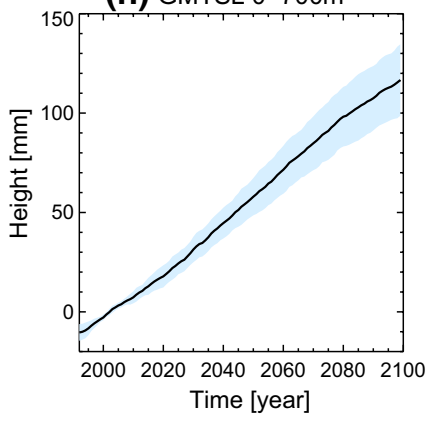

Fig. 3 Timeseries of possible predictors of the magnitude of local sea level for the historical + RCP4.5 simulations (1993-2100). a global mean surface air temperature (SAT) $\left({ }^{\circ} \mathrm{C}\right)$, b global mean sea surface temperature (SST) $\left({ }^{\circ} \mathrm{C}\right)$, c ocean volume mean temperature (OVMT300) from the surface down to $300 \mathrm{~m}\left({ }^{\circ} \mathrm{C}\right)$, d ocean volume mean temperature (OVMT700) from the surface down to $700 \mathrm{~m}$ $\left({ }^{\circ} \mathrm{C}\right)$, e ocean volume mean temperature (OVMT2000) from the surface down to $2,000 \mathrm{~m}\left({ }^{\circ} \mathrm{C}\right)$, (f) ocean volume mean temperature (OVMT Total) for the entire depth $\left({ }^{\circ} \mathrm{C}\right), \mathbf{g}$ global mean thermosteric

smoothing these time-series using a 10-year running mean. This results in an increase in correlation for all possible predictors but does not improve consistently any in particular (not shown).

For the RCP2.6 and RCP8.5 scenarios we considered as possible predictors SAT, ocean volume mean temperature for the full depth and global mean thermometric sea level for the full depth. RCP2.6 gives results with similar characteristics to RCP4.5, but SAT is consistently the best predictor for RCP8.5. We hypothesise that this is because towards the end of the twenty-first century the radiative

sea level rise (GMTSL300) from the surface down to $300 \mathrm{~m}$ (mm), h global mean thermosteric sea level rise (GMTSL700) from the surface down to $700 \mathrm{~m}$ [mm], i global mean thermosteric sea level rise (GMTSL2000) from the surface down to 2,000 $\mathrm{m}(\mathrm{mm})$, j global mean total thermosteric sea level rise (GMTSL Total) for the entire depth (mm). The lines are the CMIP5 ensemble mean. The shading represents the CMIP5 ensemble spread as 1 SD. All the time-series are relative to the 1993-2012 mean

forcing under RCP8.5 accelerates, which tends to enhance surface warming relative to deep warming, so the temporal evolution of global sea level change is better described by a predictor including only surface information. On the other hand in RCP4.5 and RCP2.6 the forcing increases steadily or at a declining rate, allowing time for penetration of heat to greater depth.

Overall, there is no variable which is consistently the best predictor of sea level change in all models and experiments, but all the predictors considered give good correlations. We decide to use the same predictor for all 
Fig. 4 Temporal correlation coefficients between the area-weighted spatial standard deviation time-series $(\mathrm{mm})$ and the sea level change predictor time series for CMIP5 historical + RCP4.5 simulations between 1993-2100. The diamonds show the mean of the correlation coefficients from the individual models. Same abbreviations as Fig. 3

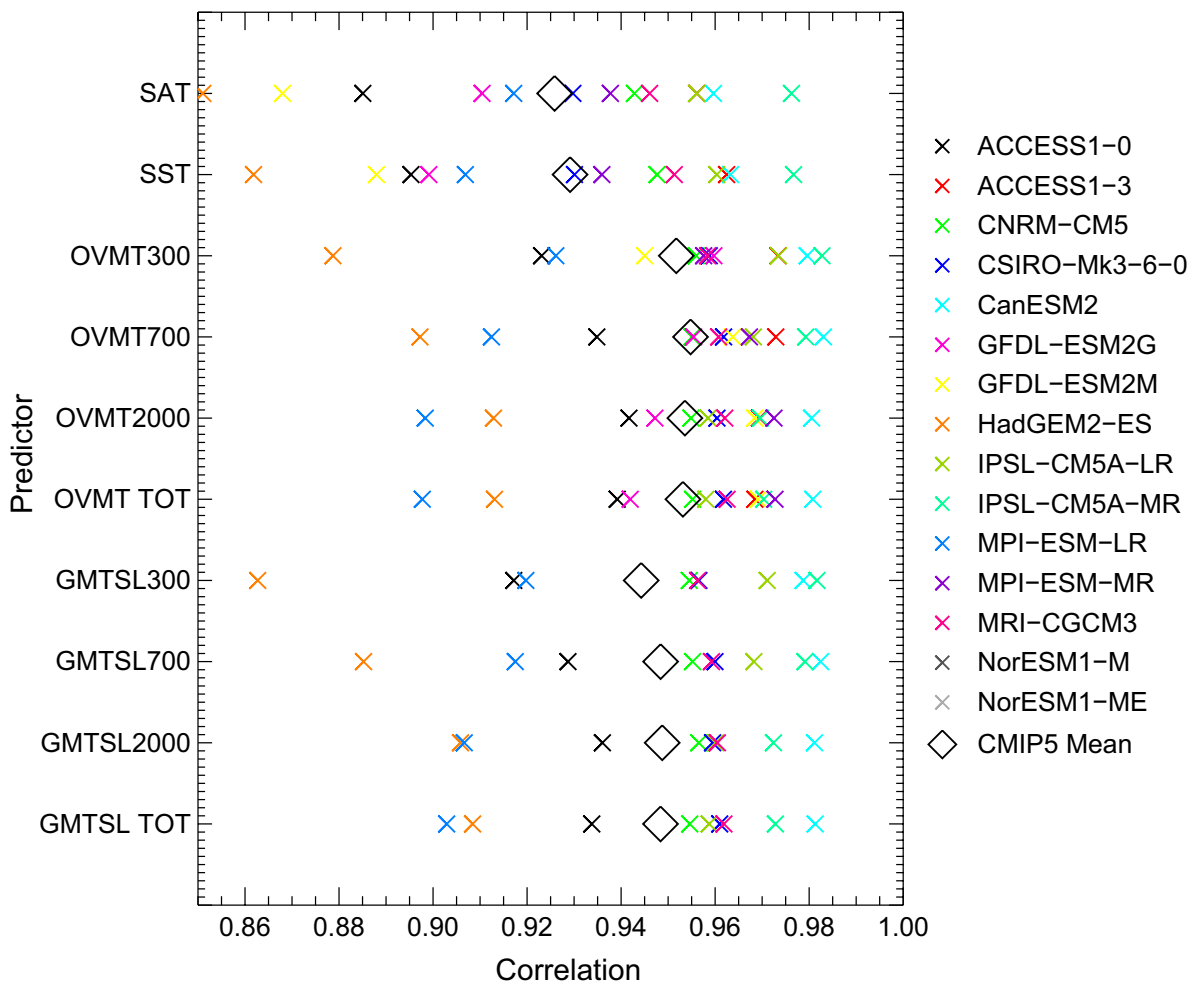

experiments, and therefore we choose ocean volume mean temperature over the total depth as our predictor, because it gives the highest model ensemble-mean correlation in both RCP2.6 and RCP4.5, and it is available for more models than thermosteric sea level. It is an advantage for our purpose in that ocean volume mean temperature over the total depth has very high signal to noise ratio.

\subsection{The pattern of sea level change}

The forced pattern of sea level change $P(\underline{x})$ was calculated by regressing the CMIP5 AOGCMs sea level change fields $\eta(x, t)$ against the predictor $S(t)$ (ocean volume mean temperature over the total depth) (Fig. 5). In the historical $+\mathrm{RCP}$ scenarios $\eta$ and $\mathrm{S}$ are calculated relative to the mean of 1993-2012. Figure 5a shows the model ensemble mean pattern of sea level change for historical + RCP4.5. There is a zonal dipole in the Southern Ocean, with a band of increased sea level north of $50^{\circ} \mathrm{S}$ and decreased sea level to the south relative to the global mean (Bouttes et al. 2012; Frankcombe et al. 2013). The North Atlantic also has a dipole pattern, with the largest increase of sea level change to the North and decreased sea level to the South (Bouttes et al. 2013a). There is a large sea level rise in the Beaufort Sea. The Pacific Ocean has a weak pattern of increased sea level in the North-West and decreased sea level in the South-East. The major features are common among CMIP5 and earlier models (Gregory et al. 2001; Lowe and Gregory
2006; Landerer et al. 2007; Meehl et al. 2007; Pardaens et al. 2011; Yin 2012; Church et al. 2013; Slangen et al. 2014). The patterns are similar for RCP2.6 and RCP8.5 (see also Sect. 3.5). Note also the similarity of the pattern of sea level change (Fig. 5a) with the pattern estimated by Perrette et al. (2013) using surface air temperature as a predictor.

For any scenario, there is a large spread among the models, as shown by the inter-model standard deviation (Fig. 5b). The other RCPs and experiments considered show similar spread to Fig. 5b. The regions with the largest spread are the Arctic, North Atlantic and Southern Ocean, where the strongest forced responses occur (Pardaens et al. 2011; Bouttes et al. 2012; Church et al. 2013).

\subsection{Accuracy of the pattern scaling method for sea level change}

Having made a best choice for the predictor $S(t)$ and determined the pattern $P(\underline{x})$, we can apply the method of pattern scaling to estimate the sea level change for 19932099 for each model and scenario in response to forcing according to $\eta_{\mathrm{PS}}(\underline{x}, t)=P(\underline{x}) S(t)$. To assess the accuracy of the method in reproducing the time-dependent forced response projected by an AOGCM, we follow a similar methodology to Mitchell (2003). We calculate annual residual fields $\Delta \eta=\eta_{\mathrm{GCM}}-\eta_{\mathrm{PS}}$, where $\eta_{\mathrm{GCM}}$ is the sea level change (relative to global mean sea level rise) given by 

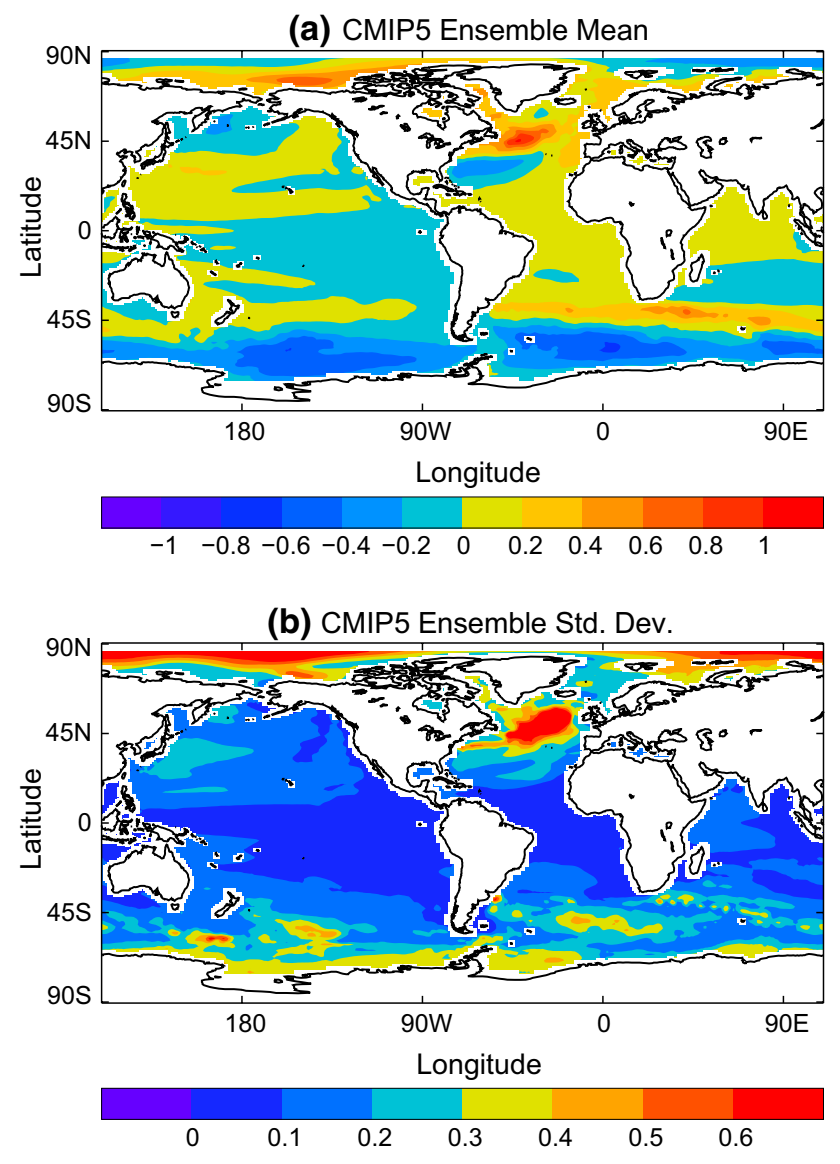

Fig. 5 a CMIP5 model ensemble mean and b standard deviation of the forced patterns of sea level change $\left(\mathrm{m} /{ }^{\circ} \mathrm{C}\right)$ calculated using ocean volume mean temperature $\left({ }^{\circ} \mathrm{C}\right)$ as predictor for the historical + RCP4.5 simulations between 1993-2099

the AOGCM, and compute the root mean square of $\Delta \eta$ at each gridbox in these fields as an indication of the typical size of the error. Figure 6 a shows the ensemble mean for historical + RCP4.5.

According to Eq. (1), these residuals should be statistically consistent with unforced internal variability $\varepsilon$. If this is not so, the assumption of pattern scaling is not valid, i.e. the processes determining local forced sea level change do not scale linearly with the global predictor (which we have chosen to be ocean volume mean temperature). We quantify $\varepsilon$ as the standard deviation of annual means of $\eta_{\text {piC }}$, which denotes $\eta_{\mathrm{GCM}}$ in the pre-industrial control run (driftcorrected). Figure $6 \mathrm{c}$ shows the CMIP5 multi-model mean of $\varepsilon$. (Since this quantity has zero time-mean by construction, its root mean square and standard deviation are equal.) In all models, unforced internal variability has the largest magnitude in the North Atlantic, Eastern Pacific and Southern Ocean. The multi-model deviation also shows the largest inter-model differences to occur in the Arctic Ocean, North Atlantic and Southern Ocean (Fig. 5b). There is a remarkable similarity between Fig. $6 a$ and $c, b$ and d, even in small details. This similarity supports the assumption that the differences between the AOGCM and pattern-scaling predictions are mainly due to unforced variability.

Because unforced interannual variability is substantial compared with the forced response, to quantify the latter it is customary to consider 20-year means (cf. Church et al. 2013; Slangen et al. 2014) (Fig. 7). Figure 7a, b show the CMIP5 ensemble mean $\eta_{\mathrm{GCM}}$ for the mean of 2080-2099 simulated by the AOGCMs and the pattern scaling prediction respectively. We assume that these 20 years of the scaling prediction suffer from the largest errors, because the forced response is small early in the twenty-first century but grows in time, but we see that $\eta_{\mathrm{PS}}$ nonetheless agrees very well with $\eta_{\mathrm{GCM}}$ in the ensemble mean.

For each model, we compare the 20-year mean of the annual residuals $\Delta \eta$ for 2080-2099 (Fig. 7c) with the magnitude of unforced variability $\varepsilon$ (Fig. 7d), quantified as the standard deviation of the 20-year time-means of $\eta_{\text {piC }}$ from non-overlapping 20-year segments of the drift-corrected pre-industrial control simulations. We test the null hypothesis that the magnitude of the residual at each point is consistent with $\eta_{\mathrm{piC}}$, assuming that the distribution of unforced variability in $\eta_{\mathrm{piC}}$ is Gaussian, at a significance level of $5 \%$ (two-tailed). Table 1 (columns for the pattern for individual scenarios) shows the percentage area where the null hypothesis is rejected i.e. the residual is significantly different from unforced internal variability, implying that the pattern-scaling method is inaccurate. For models with a single ensemble member, the test fails in less than $15 \%$ of the area. The regions with statistically significant errors are model dependent, however they tend to be most common in the Arctic Ocean, Southern Ocean and tropical Pacific Ocean.

For models with an ensemble of integrations for each scenario (CSIRO-Mk3.6.0, CanESM2 and HadGEM2-ES), we compare two different methods. In the first method, we treat each ensemble member as though it were a model by itself, and compute a pattern by regression using that ensemble member alone. Then we compute the residuals and carry out the significance test for each ensemble member, and finally we calculate the ensemble mean of the area where the test fails. This method is like the one which we use for the models where an ensemble is not available, except that each ensemble member gives us a different result, and we present the mean. The results are similar to the other models; the test fails in less than $15 \%$ of the area on average (Table 1).

The second method relies on our knowledge that the ensemble members differ only because of unforced variability, and the forced response is the same. We therefore obtain a best estimate of the pattern of the forced response by using all the ensemble members together in the linear regression. We use this single pattern with each ensemble 
Fig. 6 a Model ensemble mean $(\mathrm{mm})$ and $\mathbf{b}$ model ensemble standard deviation $(\mathrm{mm})$ of the root mean square of the annual residuals for 1993-2099 for the pattern-scaling prediction of the historical + RCP4.5. c Model pre-industrial control standard deviation multi-model ensemble mean $(\mathrm{mm})$ and $\mathbf{d}$ standard deviation $(\mathrm{mm})$

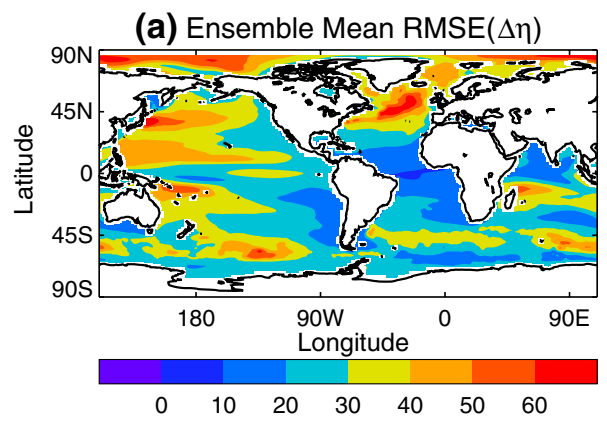

(c) Ensemble Mean $\mathrm{SD}\left(\eta_{\mathrm{pic}}\right)$

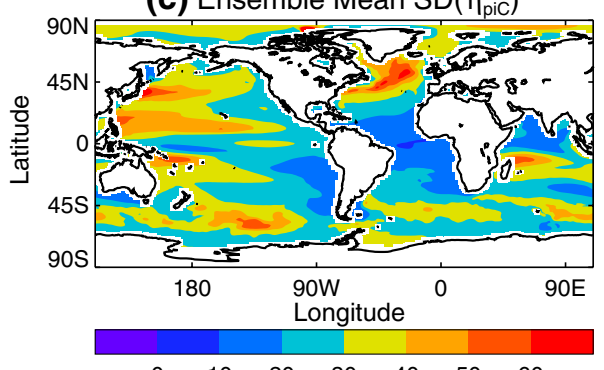

$\begin{array}{lllllll}0 & 10 & 20 & 30 & 40 & 50 & 60\end{array}$

(a) $\eta_{\mathrm{GCM}}$

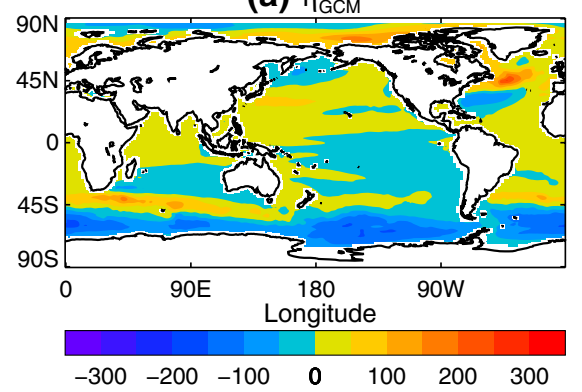

(c) $\Delta \eta$

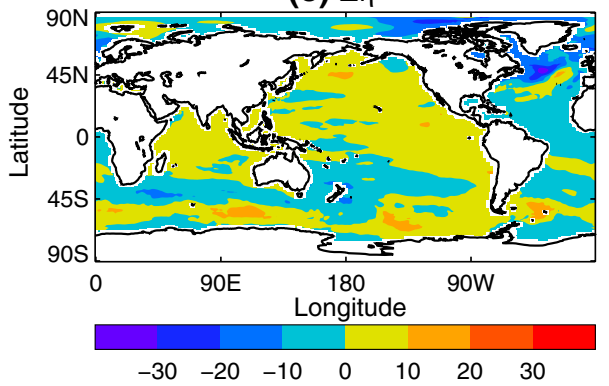

(b) Ensemble SD RMSE $(\Delta \eta)$

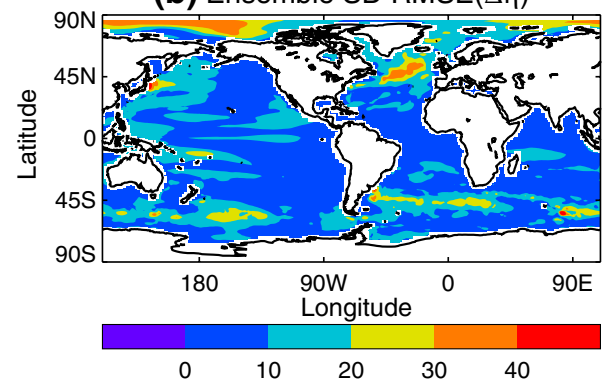

(d) Ensemble SD SD $\left(\eta_{\text {pic }}\right)$

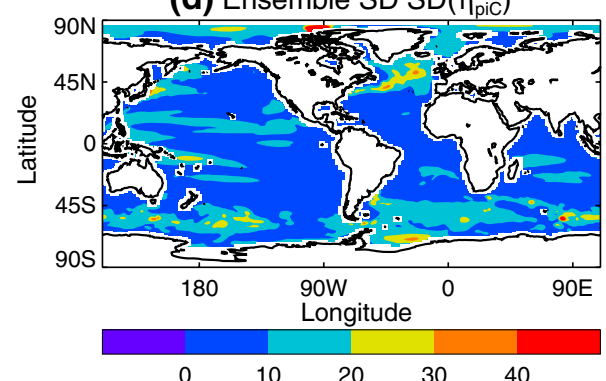

(b) $\eta_{P S}$

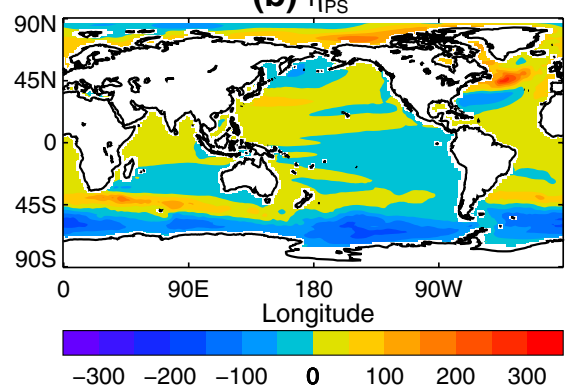

(d) $\eta_{\text {pic }} 20 y r-V a r i a b i l i t y$

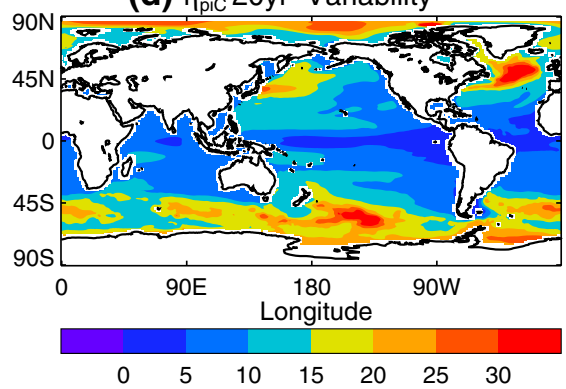

member separately to make scaling projections using the predictor time-series from that ensemble member. The subsequent steps are the same as in the first method. In the second method, the test fails in about $30 \%$ of the area in HadGEM2-ES, $35 \%$ in CanESM 2 and $40 \%$ in CSIROMk3-6-0 (Table 1), in the same regions as method 1. Because the only difference is the pattern, we conclude that when using a single ensemble member the pattern given by the regression contains some influence of the unforced variability that is specific to that ensemble member, and the residuals are therefore smaller. This is an important caveat for the use of pattern scaling using a single ensemble member. Because of this effect, the accuracy of the method may appear to be exaggerated. 
Although the results indicate statistically significant errors in pattern scaling, the magnitude of these errors is small. The area-weighted root mean square (RMS) of the residual $\Delta \eta$ mean for 2080-2099 for each model is tabulated in Table 2. It ranges within 10-15 mm (using method 1 , as described above, to compute the residuals for models where there is an ensemble). This typical size for the residual should be compared with the geographical variation of $\eta_{\mathrm{GCM}}$ for 2080-2099 relative to the 1993-2012, which lies in the range $40-60 \mathrm{~mm}$ for RCP2.6 and $80-110 \mathrm{~mm}$ for RCP8.5 (Table 2), except for one model (MRI-CGCM3, which predicts smaller sea level changes). Part of the residual is due to unforced variability, which the patternscaling method does not reproduce, and part could be due to pattern scaling errors. For comparison with $\operatorname{RMS}(\Delta \eta)$, we compute the area-weighted RMSs of 20-year means of $\eta_{\mathrm{GCM}}$ from pre-industrial control simulations $\left(\eta_{\mathrm{piC}}\right)$ for each CMIP5 model, and calculate the mean and standard deviation of the results from all 20-year segments. This quantity indicates the magnitude of unforced variability in 20-year means. These values (Table 2) are generally of similar magnitude values to those for the RMS of the residual fields, suggesting the errors will not be distinguishable from internal variability, consistent with the result above that the errors are significant in only a small fraction of the total area. Furthermore, we note that $\operatorname{RMS}(\Delta \eta)$ is no larger for RCP8.5 than RCP2.6, indicating that it is dominated by unforced variability, because we would expect larger pattern-scaling errors for the greater forced response expected in RCP8.5.

For the three models where we have multiple ensemble members, we also compute the ensemble-mean RMS error from the residuals using method 2 (above) to make the scaling projections, with a single pattern computed from all ensemble members. These values (Table 2) are in the range 20-30 mm, about twice the size as from method 1 . This indicates that the errors are larger when a single pattern is used, consistent with the larger area in which the residuals were found above to be significant. This reinforces the conclusion that the use of a single ensemble member will underestimate the errors in predicting the forced response. Nonetheless $\operatorname{RMS}(\Delta \eta)$ is still less than half the size of $\operatorname{RMS}\left(\eta_{\mathrm{GCM}}\right)$ in RCP2.6 and less than one-third in RCP8.5 in these three models.

\subsection{Is the pattern of sea level change independent of scenario?}

We examine whether the forced pattern of sea level change is the same in the different Historical + RCP scenarios. The spatial correlation between patterns for pairs of scenarios in a given model is about 0.8 or more between RCP2.6 and the other two scenarios, and about 0.9 or more between
RCP4.5 and RCP8.5 (Table 3). To determine whether the differences in the patterns estimated for the scenarios could be due to unforced internal variability, we make use of those models with several ensemble members: CSIROMk3.6.0, CanESM2 and HadGEM2-ES (Table 1). In these models, for each scenario, we can determine a pattern by regression from each ensemble member individually (method 1), as well as for all ensemble members together (method 2). For method 1, we report the mean correlation between all possible pairs of patterns. The correlations in method 1 are similar to those for the models without ensembles, whereas the correlations in method 2 are considerably higher (Table 3 ). This suggests that the differences in the forced pattern between scenarios is small, but that the pattern from a single member contains some fingerprint of unforced variability specific to that member. When using method 2 to calculate the patterns a large amount of this unforced internal variability is eliminated, increasing the correlation between scenarios in general. Some differences between scenarios remain, as shown by the lower correlations between the RCP2.6 and RCP8.5 pattern even in method 2.

Although the pattern of sea level change may be not completely independent of scenario, it would be practically useful for the purposes of prediction using the scaling method if it can be treated as such. This is likely to be a good assumption only under scenarios with similar time forcing profile (Bouttes et al. 2013b).

To test the consequences of this, we computed a single pattern for each model using all the ensemble members of every RCP in the linear regression at once. Then using this pattern we can reconstruct sea level fields and analyse the residuals for each RCP using the same method as before. The results are shown in Tables 1 and 2 (columns labeled all-RCP pattern). The percentage area where the residuals are significant and the RMS error are greater than before, and are of similar sizes to those we obtained for a single RCP using method 2 with the models for which we have ensembles. We conclude that the main reason for the greater inaccuracy is that influence of unforced variability on the estimate of the forced pattern of response has been reduced, because the three RCPs together form an ensemble of three independent integrations. It may seem paradoxical that use of an ensemble gives larger (rather than smaller) errors in the scaling predictions for the forced response; the reason, as for the comparison between methods 1 and 2, is that the use of a single ensemble member to derive the pattern and then use it to estimate $\eta$ gives residuals which are biased low, because there is some unforced variability which affects both the pattern and the predictor in a correlated way. There must be an additional error because of the small differences in the forced patterns for different scenarios, but this is comparatively unimportant. 
Table 2 CMIP5 AOGCM area-weighted root mean square of $\eta(\mathrm{mm})$ for the time-mean of 2080-2099 and area-weighted root mean square of $\Delta \eta(\mathrm{mm})$, the difference between the prediction by the pattern scal-

The column labelled RMS $\left(\eta_{\mathrm{piC}}\right)$ show the mean and standard deviation of the area-weighed RMS of sea level fields $\eta_{\mathrm{GCM}}$ in non-overlapping 20-year segments of the pre-industrial control simulation

Hence for practical purposes it is adequate to use a single pattern for all RCPs, and one could argue that it is actually preferable.

\section{Detecting the pattern of sea level change}

In this section we address the question of when the forced pattern of sea level change due to ocean circulation and density changes will emerge from the noise of unforced variability i.e. when will it be statistically detectable. To do this we use two methods, described in the following subsections.

\subsection{Global time of emergence}

We first consider the global time of emergence, i.e. when the global pattern of sea level change emerges from

ing method and the AOGCM simulation of sea level change relative to the global mean in the time-mean of 2080-2099 relative to 1993-

\begin{tabular}{|c|c|c|c|c|c|}
\hline \multicolumn{3}{|c|}{ RCP4.5 } & \multicolumn{3}{|l|}{ RCP8.5 } \\
\hline $\begin{array}{l}\text { RMS } \\
\left(\eta_{\mathrm{GCM}}\right) \\
(\mathrm{mm})\end{array}$ & $\begin{array}{l}\operatorname{RMS}(\Delta \eta \\
)(\mathrm{mm}) \\
\mathrm{RCP} 4.5\end{array}$ & $\begin{array}{l}\mathrm{RMS}(\Delta \eta \\
)(\mathrm{mm}) \text { all- } \\
\mathrm{RCP}\end{array}$ & $\begin{array}{l}\text { RMS } \\
\left(\eta_{\mathrm{GCM}}\right) \\
(\mathrm{mm})\end{array}$ & $\begin{array}{l}\text { RMS ( }(\Delta \eta \\
)(\mathrm{mm}) \\
\operatorname{RCP} 8.5\end{array}$ & $\begin{array}{l}\text { RMS ( } \Delta \eta \\
)(\mathrm{mm}) \\
\text { all-RCP }\end{array}$ \\
\hline 77 & 16 & - & 110 & 18 & - \\
\hline 69 & 15 & - & 87 & 20 & - \\
\hline 48 & 7 & 11 & 69 & 9 & 19 \\
\hline 71 & 11 & - & 100 & 11 & - \\
\hline & 23 & 23 & & 22 & 28 \\
\hline
\end{tabular}


Table 3 Spatial correlation between patterns from RCP experiments

\begin{tabular}{llllllllll}
\hline Models & RCP2.6 & RCP4.5 & RCP8.5 & RCP2.6-RCP4.5 & RCP2.6-RCP8.5 & RCP4.5-RCP8.5 & RCP2.6-All & RCP4.5-All & RCP8.5-All \\
\hline CNRM-CM5 & - & - & - & 0.94 & 0.86 & 0.95 & 0.94 & 0.99 & 0.98 \\
CSIRO-Mk3-6-0 & 0.85 & 0.89 & 0.95 & $0.86 / 0.98$ & $0.84 / 0.93$ & $0.90 / 0.98$ & 0.97 & 1.00 & 0.99 \\
CanESM2 & 0.83 & 0.86 & 0.94 & $0.86 / 0.99$ & $0.86 / 0.95$ & $0.90 / 0.98$ & 1.00 & 0.99 & 0.95 \\
GFDL-ESM2M & - & - & - & 0.97 & 0.90 & 0.95 & 0.96 & 0.99 & 0.98 \\
HadGEM2-ES & 0.82 & 0.85 & 0.92 & $0.82 / 0.94$ & $0.77 / 0.85$ & $0.87 / 0.96$ & 1.00 & 0.94 & 0.85 \\
IPSL-CM5A-LR & - & - & - & 0.88 & 0.78 & 0.94 & 0.87 & 0.98 & 0.98 \\
IPSL-CM5A-MR & - & - & - & 0.93 & 0.78 & 0.93 & 0.89 & 0.98 & 0.98 \\
MPI-ESM-LR & - & - & - & 0.83 & 0.74 & 0.95 & 0.85 & 0.99 & 0.98 \\
MPI-ESM-MR & - & - & - & 0.91 & 0.83 & 0.95 & 0.91 & 0.98 & 0.98 \\
MRI-CGCM3 & - & - & - & 0.92 & 0.84 & 0.93 & 0.92 & 0.98 & 0.98 \\
NorESM1-M & - & - & - & 0.94 & 0.90 & 0.95 & 0.95 & 0.98 & 0.99 \\
NorESM1-ME & - & - & - & 0.96 & 0.92 & 0.96 & 0.97 & 0.99 & 0.99 \\
\hline
\end{tabular}

The first three columns of results are the mean correlations between ensemble members of the same RCP; this can be computed only for those models with ensembles. The following three columns show the correlation between patterns of different scenarios. For the models where we have multiple runs the first number is the ensemble mean correlation computing the patterns using method 1 , while the second number is the correlation computing one pattern using method 2 . The last three columns shows the correlation between patterns for each scenario and the single pattern calculated by using all scenarios in a similar way to method 2

of correlation coefficients between the pattern of sea level change $P$ and $\eta_{\mathrm{GCM}}$ in the AOGCM pre-industrial control simulation (drift corrected) (Fig. 8). When this threshold is permanently exceeded, we conclude that there is a statistically significant similarity and therefore that the signal of the anthropogenic climate change in the pattern of sea level would be detectable. As Fig. 8 shows, the model mean 97.5th percentile of correlation coefficients is approximately 0.3 for all RCP scenarios, indicating that there is weak correlation of the pattern $P$ with unforced internal variability. We note that global mean sea level change is not included and does not affect the results, since the correlation coefficient of two fields is not changed by adding a uniform value to either field.

Table 4 shows the ensemble mean time of emergence of local sea level change and its inter-model standard deviation. For the historical + RCP scenarios, the forced pattern of sea level change (relative to the 1993-2012 mean) could emerge in the next few years, or has already done so, according to the CMIP5 models. The times of emergence for the various RCP scenarios are statistically indistinguishable, because the CMIP5 spread early in this century is dominated by unforced variability and differences among models, rather than by the spread of RCP scenarios, which do not diverge markedly for several decades (Hawkins and Sutton 2012). The divergence is later for sea level change than for surface climate parameters, because of the thermal inertia of the ocean (Church et al. 2013). Examining the spread of the global time of emergence within the ensemble for the three models suggests that differences between models are likely to be the dominant cause of the spread rather than unforced variability.

The model-mean global time of emergence for historical + RCP4.5 is 2016, only 3 years after the end of our 20 -year reference period. To test whether this closeness is a coincidence, we also evaluate the global time of emergence in this scenario using the 10-year reference period 1993 2002 (Table 4). This is the information which would have been available if the same analysis had been done about 10 years ago. The model-mean global time of emergence is 6 years after the end of the 10 -year reference period i.e. the delay is longer.

We also repeat the analysis excluding the Pacific and excluding the Southern Ocean (Table 4). Excluding the Pacific makes no significant difference, because the models do not indicate a strong forced pattern in that region, even though the observed trends are not consistent with unforced variability (Sect. 2). The Southern Ocean, however, shows a forced signal common to the models. Excluding it delays the global time of emergence, but only by 3 years on average. Evidently the signal emerges significantly in other regions quite quickly.

\subsection{Local time of emergence of sea level change}

Although the global time of emergence is relatively soon, the time of emergence could vary locally. We also examine the local time of emergence, which depends not only on the pattern but also on the global mean sea level. The local time of emergence is an indicator of when sea level 
(a) Historical+RCP2.6

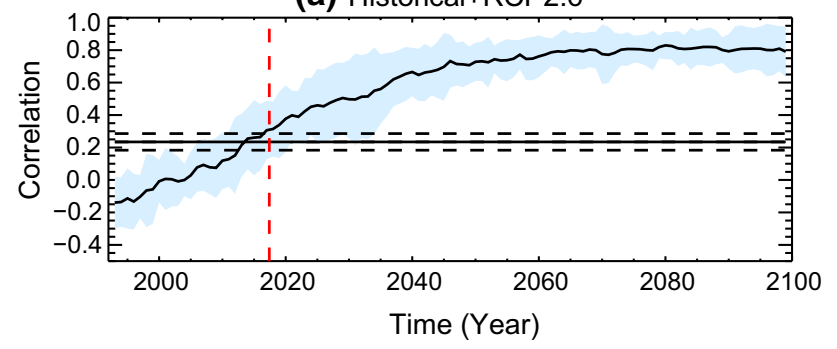

(b) Historical+RCP4.5

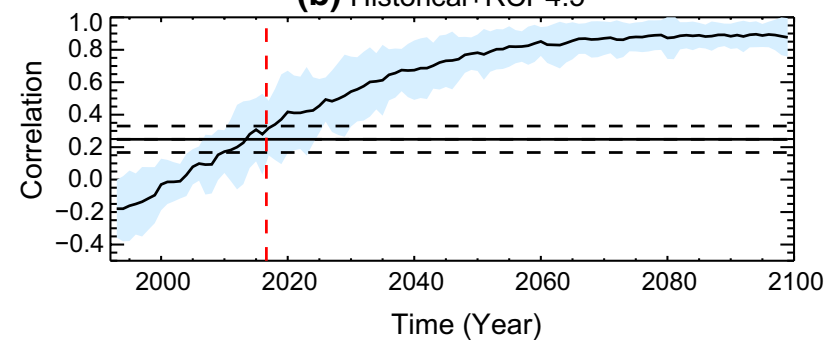

(c) Historical+RCP8.5

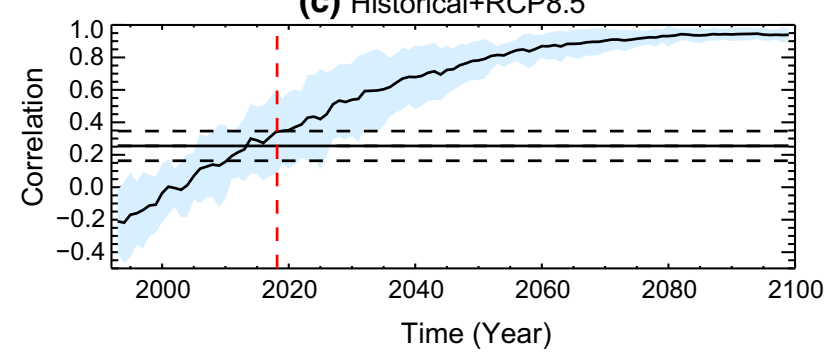

Fig. 8 Global year of emergence of the forced pattern of sea level change, relative to the time-mean of the altimeter period (1993-2012), for the historical + RCPs (1993-2099): a Historical + RCP2.6, b Historical + RCP4.5 and c Historical + RCP8.5. The solid increasing line is the model ensemble mean correlation between the pattern $P$ of sea level change estimated from pattern scaling with the annual-mean CMIP5 scenario sea level change fields $\eta_{\mathrm{GCM}}$. The shading shows the model spread ( $\left.\pm 1 \mathrm{SD}\right)$. The solid horizontal line represents the ensemble mean 97.5 th percentile threshold, calculated by correlating the pattern of sea level change with the CMIP5 pre-industrial control simulations. The dashed lines show the model spread $( \pm 1 \mathrm{SD})$ in the threshold

change will become of practical significance, because it has gone outside the range of unforced variability to which infrastructure and ecosystems are adapted. Hawkins and Sutton (2012) determined when the signal of anthropogenic climate change in surface air temperature emerges from unforced variability by calculating a signal to noise ratio $(\mathrm{S} / \mathrm{N})$. Here we apply a similar methodology to sea level change due to the anthropogenic influence on ocean circulation and density. Once again we note that we do not include the sea level change due to effects such as modifications of the geopotential field and lithosphere flexure resulting from loss of land-ice (Slangen et al. 2012, 2014; Perrette et al. 2013). (These effects could make the time of emergence earlier or later, according to whether they have 
the same or opposite sign to the effects of ocean circulation and density.) Lyu et al. (2014) show that the local time of emergence of sea level change is generally earlier when they are included.

The local time of emergence is obtained for the historical and RCP scenarios, for sea level change relative to the 1993-2012 mean. First, the forced signal is calculated as $h_{\mathrm{GCM}}(t)+\eta_{\mathrm{PS}}(\underline{x}, t)$, where $h_{\mathrm{GCM}}$ is the global mean thermosteric sea level change from the AOGCM, which is added uniformly to $\eta_{\mathrm{PS}}$ from the pattern-scaling method. The reason for using $\eta_{\mathrm{PS}}$ (rather than $\eta_{\mathrm{GCM}}$ ) is that that the unforced variability is reduced, thus increasing the accuracy of the estimate of time of emergence (Hawkins and Sutton 2012). Because both $h_{\mathrm{GCM}}$ and ocean volume mean temperature, the predictor variable in the pattern-scaling method, relate to the heat content of the entire ocean, they have very little unforced inter-annual variability (Fig. 3). Then the signal to noise ratio is calculated by dividing the forced signal by the pre-industrial control (drift corrected) interannual standard deviation. We define the local time of emergence as the year when the signal to noise ratio permanently goes outside the $2.5-97.5 \%$ range of unforced variability, that is, the threshold values are -1.96 and 1.96 . If the signal to noise ratio is outside this range, sea level change is inconsistent with unforced internal variability with $95 \%$ confidence.

The multi-model ensemble mean for the historical + RCP4.5 (Fig. 9a) shows that the local time of emergence is earliest in the tropical Atlantic Ocean and Indian Ocean, consistently among the models, as shown by the low ensemble standard deviation (Fig. 9b). In most regions the signal of forced sea level change will emerge by approximately 2050, with the exception of the Southern Ocean (Fig. 9a). Like the global time of emergence, the local time of emergence shows small differences between scenarios. The main differences occur in regions where the local time of emergence is late, especially the Southern Ocean and Western Pacific. There are remarkable similarities with the results of Lyu et al. (2014) who use a different methodology, although the results are not exactly comparable since they use a different time period.

Not surprisingly, there is substantial similarity between the local time of emergence (Fig. 9a) and unforced internal variability (Fig. 6c). An earlier time of emergence could be explained by either large signal or small noise (or a combination of both). In the tropical Atlantic region, where the time of emergence is earliest, and some models even suggest that the forced signal is already detectable, the emergence is early due to the low unforced variability. Hawkins and Sutton (2012) made a similar observation for the early time of emergence of surface air temperature change in the tropics. They investigated whether this occurs as a result of grid-cell size (larger grid-cells over the tropics and thus (a) Local Time of Emergence Ensemble Mean

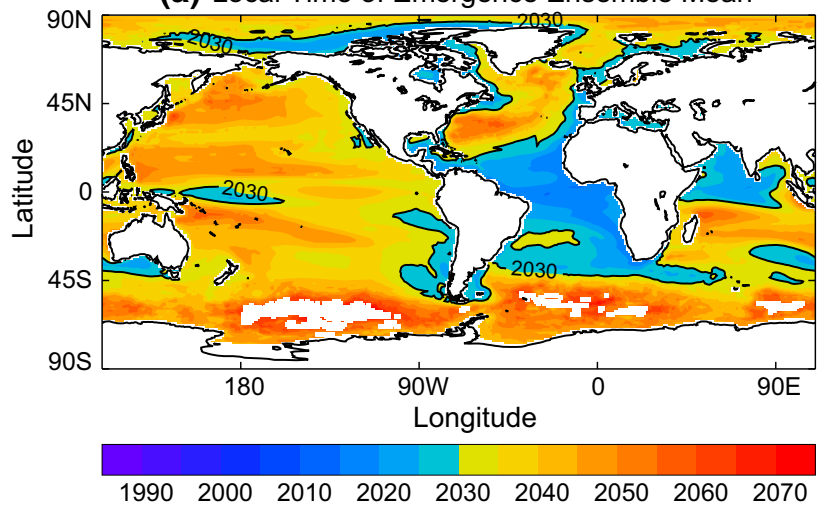

(b) Local Time of Emergence Ensemble Std. Dev.

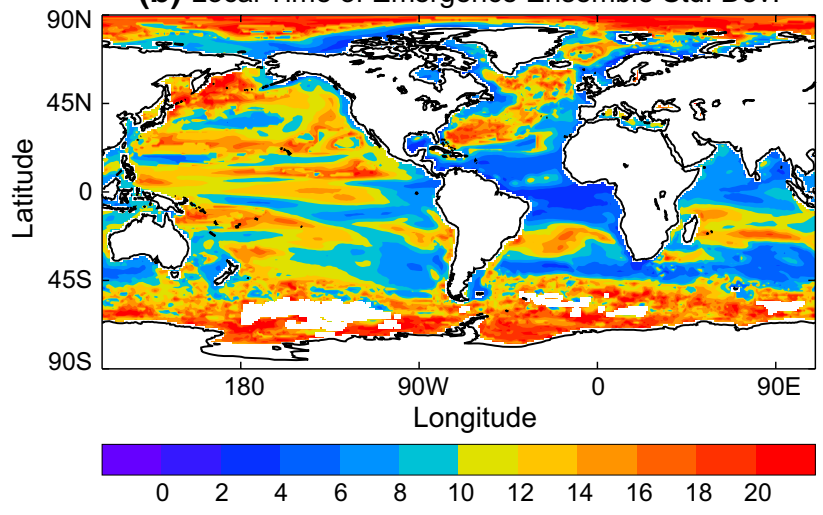

Fig. 9 Local year of emergence of the forced pattern of sea level change in historical + RCP4.5. a CMIP5 ensemble mean and b standard deviation. Sea level change is computed with respect to the time-mean of the altimeter period (1993-2012). The white areas represent regions where forced sea level change will not emerge by 2099 in at least $1 / 3$ of the models

may result in smaller internal variability), and concluded that this was not a significant effect. We expect the same applies to sea level change.

The local time of emergence is earlier in the Eastern Pacific than the Western Pacific, matching the pattern of unforced internal variability (Fig. 6c). However, as discussed in previous sections, CMIP5 models may underestimate the magnitude of unforced internal variability in the tropical Pacific. If so, the local time of emergence should be later in those regions than indicated by the models.

In contrast, the local time of emergence of sea level change change in the Southern Ocean is later than 2100 because the signal is small compared with the noise. Most models show that sea level will rise least in southern latitudes of the Southern Ocean and in fact it may fall by 2100 . Note that, with respect to the global mean, $\eta$ is negative in this region, thus opposing $h_{\mathrm{GCM}}$. Thus, forced local sea level change is hard to detect in this region by itself, whereas in Sect. 2 we noted that the meridional contrast in $\eta$ across the Southern Ocean is a robust pattern and may 
be detectable earlier. It is also remarkable how the intermodel standard deviation of local sea level change is lower along the increased sea level band at approximately $45^{\circ} \mathrm{S}$; all models predict a fairly early time of emergence of the signal in these latitudes.

\section{Summary and conclusion}

Future sea level rise due to ocean density and circulation change predicted by AOGCMs is not spatially uniform. For instance, the area-weighted standard deviation of local sea level change under scenario RCP8.5 for 2080-2099 relative to $1993-2012$ is $80-110 \mathrm{~mm}$, depending on the model, which is substantial compared with the global mean sea level rise of 190-300 $\mathrm{mm}$ due to thermal expansion.

We apply and evaluate the method of pattern scaling for historical and RCP simulations from CMIP5 AOGCMs of local sea level change relative to global mean sea level change. This method assumes that forced sea level change has a constant pattern and that its amplitude increases with time i.e. $\eta(\underline{x}, t)=P(\underline{x}) S(t)+\varepsilon(\underline{x}, t)$, where $P(\underline{x})$ is the pattern, which is a function only of location $x, S(t)$ is a predictor variable, which is a function only of time $t$, and $\varepsilon(\underline{x}, t)$ is unforced variability. The main advantage of this method is that it provides a way to estimate local forced sea level change with negligible unforced internal variability.

We find that the best choice of predictor $S$ depends on model and scenario; for RCP2.6 and RCP4.5 ocean volume mean temperature or global mean thermosteric sea level are best, whereas for RCP8.5 surface temperature is better. The differences between the pattern-scaling estimate and the AOGCM results for a single model integration are mostly consistent with unforced variability, indicating that the method is accurate. However, considering the cases where we have an ensemble of integrations and using them all together to estimate the pattern $P$, we find that the typical size of the difference in $\eta$ between pattern-scaling and AOGCM is approximately doubled, at $20-30 \mathrm{~mm}$. We suggest that this is because there is a stronger imprint of unforced variability in the pattern estimated from a single integration, and evaluating the errors in pattern-scaling from a single integration may thus exaggerate the accuracy of the method. This caveat may apply to the pattern scaling method when applied to other quantities.

The patterns from different RCP scenarios are very similar. The major features are the contrast in the Southern Ocean between a band of increased sea level north of $50^{\circ} \mathrm{S}$ and decreased sea level to the south, and a dipole in the North Atlantic. For practical purposes, computing one pattern from all scenarios is advantageous, because the pattern computed from all RCPs together can be expected to be less noisy, and the method can then be applied to scenarios for which AOGCM results are not available. However, this will be accurate only for scenarios with similar temporal profiles (cf. Bouttes et al. 2013b), and the patterns computed for the twenty-first century may not be applicable for later centuries.

We perform a detection study with the objective of determining whether the observed geographical pattern of sea level change can be explained by unforced internally generated variability or whether we can detect the signal of an external forcing. By comparing satellite altimeter observations of sea level change since 1993 with historical and pre-industrial control simulations of CMIP5 climate models, we conclude that the observed pattern of trends is dominated by unforced internal variability in most regions. The observed trends in the tropical Pacific Ocean are inconsistent with simulated unforced variability, but we suggest that the CMIP5 models may underestimate the magnitude of unforced sea-level variability in this region (cf. England et al. 2014). However, the dipole pattern observed in the Southern Ocean is likely to be associated with anthropogenic forcing because it is a robust feature of both historical and future simulations and inconsistent with unforced variability.

Using the forced patterns obtained in the pattern-scaling method we calculate the global and local times of emergence to determine when sea level change (with respect to the time-mean of 1993-2012) will be detectable above the noise of unforced internally generated variability in the RCP projections. We define the global time of emergence as the year when the area-weighted spatial correlation coefficient between the annual sea level change field and the time-independent forced pattern $P$ becomes inconsistent with unforced variability. By this definition, the forced pattern is expected to emerge within the next decade. We define the local time of emergence as the year when local sea level change due to ocean density and circulation change (the sum of $\eta$ in global mean thermal expansion) becomes inconsistent with unforced variability. Local sea level change will emerge first, and may have already emerged, in the northern latitudes of the Southern Ocean, and in the tropical Atlantic, where unforced variability is small, but it may not emerge until after 2100 in southern latitudes of the Southern Ocean, where sea level change is projected to be small. The global time of emergence is delayed by a couple of years if the Southern Ocean is excluded. It is interesting to note that the global and local times of emergence are independent of RCP scenario, since the signal emerges early in the twenty-first century, when the RCP scenarios have not yet significantly diverged.

In this study we consider only the geographical pattern of sea level change as a result of density and circulation changes. However, by the end of the twenty-first century other processes (especially the loss of land ice affecting the 
geoid and lithosphere) may have a substantial influence on the geographical pattern (Perrette et al. 2013; Slangen et al. 2014), and thus modify the local time of emergence. Net loss of land ice is projected to contribute to global mean sea level rise, and will make the local times of emergence of sea level change earlier everywhere.

Acknowledgments We thank Matthew Palmer and Sea Level Meetings attendees for their useful suggestions. For their roles in producing, coordinating, and making available the CMIP5 model output, we acknowledge the climate modelling groups (listed in Table 1), the World Climate Research Programmes (WCRP) Working Group on Coupled Modelling (WGCM), and the GlobalOrganization for Earth SystemScience Portals (GO-ESSP). We also acknowledge AVISO for making available the satellite altimeter product. The research leading to these results has received funding from the European Research Council under the European Community's Seventh Framework Programme (FP7/2007-2013), ERC grant agreement number 247220, project 'Seachange'. R. Bilbao was supported by the Natural Environmental Research Council and MetOffice. We thank the two anonymous reviewers for their comments which helped improve this manuscript.Open Access This article is distributed under the terms of the Creative Commons Attribution License which permits any use, distribution, and reproduction in any medium, provided the original author(s) and the source are credited.

\section{Appendix: Sea level drift removal in the CMIP5 models}

The sea level variable 'zos' of the CMIP5 models refers to sea surface height above the geoid. In the CMIP5 database, zos can have a time-dependent geographically uniform offset, so we first subtract the global mean of each annual field. For scenario experiments, sea level change $\eta$ is calculated as a difference between its value in the scenario experiment and the value estimated from a linear function of time fitted to the parallel pre-industrial control simulation, at each gridpoint. A linear fit is subtracted, rather than the control time-series itself, in order to avoid increasing the temporal variability in $\eta$. For the control experiment itself, which we use to estimate the magnitude of unforced variability, at each grid point we subtract a linear fit to the entire length available. A higher order polynomial was not used because temporal variability in local sea level is large compared with the drift.

The global mean sea level change time series, 'zostoga', were obtained from the online supplementary dataset of (Church et al. 2013), who remove the drift from the control timeseries by subtracting a polynomial function of time. Global ocean volume mean temperature, 'thetaoga', was treated similarly.

\section{References}

Bamber J, Riva R (2010) The sea level fingerprint of recent ice mass fluxes. Cryosphere 4:621-627
Bindoff NL, Willebrand J, Artale V, Cazenave A, Gregory JM, Gulev S, Hanawa K, Le Quéré C, Levitus S, Nojiri Y, Shum CK, Talley LD, Unnikrishnan AS (2007) Observations: oceanic climate change and sea level. In: Solomon S, Qin D, Manning M, Chen Z, Marquis M, Averyt KB, Tignor M, Miller HL (eds) Climate change 2007: the physical science basis. Contribution of working group I to the fourth assessment report of the intergovernmental panel on climate change. Cambridge University Press, Cambridge

Bouttes N, Gregory JM (2014) Attribution of the spatial pattern of $\mathrm{CO}_{2}$-forced sea level change to ocean surface flux changes. Environ Res Lett 9:034004. doi:10.1088/1748-9326/9/3/034004

Bouttes N, Gregory JM, Kuhlbrodt T, Suzuki T (2012) The effect of windstress change on future sea level change in the Southern Ocean. Geophys Res Lett 39:L23602. doi:10.1029/201 2GL054207

Bouttes N, Gregory JM, Kuhlbrodt T, Smith RS (2013a) The drivers of projected North Atlantic sea level change. Clim Dyn. doi:10.1007/s00382-013-1973-8

Bouttes N, Gregory JM, Lowe JA (2013b) The reversibility of sea level rise. J Clim 26:2502-2513. doi:10.1175/JCLI-D-12-00285.1

Bryan K (1996) The steric component of sea level rise associated with enhanced greenhouse warming: a model study. Clim Dyn 12:545-555

Cai W (2006) Antarctic ozone depletion causes an intensification of the southern ocean super-gyre circulation. Geophys Res Lett 33:L03712. doi:10.1029/2005GL024911

Carton JA, Giese BS, Grodsky SA (2005) Sea level rise and the warming of the oceans in the simple ocean data assimilation (SODA) ocean reanalysis. J Geophys Res Oceans 110:C09006

Cazenave A, Nerem RS (2004) Present-day sea level change: observations and causes. Rev Geophys 42:RG3001

Church JA, White NJ (2011) Sea-level rise from the late 19th to the early 21st century. Geophys Surv 32:585-602. doi:10.1007/ s10712-011-9119-1

Church JA, White NJ, Konikow LF, Domingues CM, Cogley G, Rignot E, Gregory JM, Van den Broeke MR, Monaghan AJ, Velicogna I (2011) Revisiting the Earth's sea-level and energy budgets from 1961 to 2008. Geophys Res Lett 38:L18601. doi:10.102 9/2011GL048794

Church JA, Clark PU, Cazenave A, Gregory JM, Jevrejeva S, Levermann A, Merrifield MA, Milne GA, Nerem RS, Nunn PD, Payne AJ, Pfeffer WT, Stammer D, Unnikrishnan AS (2013) Sea level change. In: Stocker TF, Qin D, Plattner GK, Tignor M, Allen SK, Boschung J, Nauels A, Xia Y, Bex V, Midgley PM (eds) Climate change 2013: the physical science basis. Contribution of working group I to the fifth assessment report of the intergovernmental panel on climate change. Cambridge University Press, Cambridge

Collins M, Knutti R, Arblaster JM, Dufresne J, Fichefet T, Friedlingstein P, Gao X, Gutowski WJ, Johns T, Krinner G, Shongwe M, Tebaldi C, Weaver AJ, Wehner M (2013) Long-term climate change: projections, commitments and irreversibility. In: IPCC WG1 fifth assessment report, chap 12. Cambridge University Press, Cambridge, United Kingdom and New York, NY, USA

England MH, McGregor S, Spence P, Meehl GA, Timmermann A, Cai W, Gupta AS, McPhaden MJ, Purich A, Santoso A (2014) Recent intensification of wind-driven circulation in the Pacific and the ongoing warming hiatus. Nat Clim Change 4(3):222-227

Frankcombe LM, Spence P, Hogg AM, England MH, Griffies SM (2013) Sea level changes forced by Southern Ocean winds. Geophys Res Lett 40(21):5710-5715

Fyfe JC, Saenko OA, Zickfeld K, Eby M, Weaver AJ (2007) The role of poleward-intensifying winds on Southern Ocean warming. J Clim 20:5391-5400. doi:10.1175/2007JCLI1764.1

Gregory JM (2000) Vertical heat transports in the ocean and their effect on time-dependent climate change. Clim Dyn 16:501-515. doi: $10.1007 / \mathrm{s} 003820000059$ 
Gregory JM, Church JA, Boer GJ, Dixon KW, Flato GM, Jackett DR, Lowe JA, O'Farrell SP, Roeckner E, Russell GL, Stouffer RJ, Winton M (2001) Comparison of results from several AOGCMs for global and regional sea-level change 1900-2100. Clim Dyn $18: 225-240$

Gregory JM, White NJ, Church JA, Bierkens MFP, Box JE, Van den Broeke MR, Cogley JG, Fettweis X, Hanna E, Huybrechts P, Konikow LF, Leclercq PW, Marzeion B, Oerlemans J, Tamisiea ME, Wada Y, Wake LM, Van de Wal RSW (2013) Twentiethcentury global-mean sea-level rise: Is the whole greater than the sum of the parts? J Clim 26:4476-4499. doi:10.1175/ JCLI-D-12-00319.1

Griffies SM, Yin J, Durack PJ, Goddard P, Bates SC, Behrens E, Bentsen M, Bi D, Biastoch A, Bning CW, Bozec A, Chassignet E, Danabasoglu G, Danilo S, Domingues CM, Drange H, Farneti R, Fernandez E, Greatbatch RJ, Holland DM, Ilicak M, Large WG, Lorbacher K, Lu J, Marsland SJ, Mishra A, Nurser AJG, Salas y Mélia D, Palter JB, Samuels BL, Schrter J, Schwarzkopf FU, Sidorenko D, Treguier AM, heng Tseng Y, Tsujino H, Uotila P, Valcke S, Aurore Voldoir QW, Winton M, Zhang X (2014) An assessment of global and regional sea level for years 19932007 in a suite of interannual core-II simulations. Ocean Model 78:35-89

Hawkins E, Sutton R (2012) Time of emergence of climate signals. Geophys Res Lett 39:0094-8276. doi:10.1029/2011GL050087

Katsman CA, Hazeleger W, Drijfhout SS, van Oldenborgh GJ, Burgers G (2008) Climate scenarios of sea level rise for the northeast atlantic ocean: a study including the effects of ocean dynamics and gravity changes induced by ice melt. Clim Change 91:351-374

Kopp R, Mitrovica J, Griffies S, Yin J, Hay C, Stouffer R (2010) The impact of Greenland melt on local sea levels: a partially coupled analysis of dynamic and static equilibrium effects in idealized water-hosing experiments. Clim Change 103(3-4):619-625. doi:10.1007/s10584-010-9935-1

Kuhlbrodt T, Gregory JM (2012) Ocean heat uptake and its consequences for the magnitude of sea level rise and climate change. Geophys Res Lett 39:L18608. doi:10.1029/2012GL052952

Landerer FW, Jungclaus JH, Marotzke J (2007) Ocean bottom pressure changes lead to a decreasing length-of-day in a warming climate. Geophys Res Lett 34:L06307. doi:10.1029/2006GL029106

Lowe JA, Gregory JM (2006) Understanding projections of sea level rise in a Hadley Centre coupled climate model. J Geophys Res 111:C11014. doi:10.1029/2005JC003421

Lyu K, Zhang X, Church JA, Slangen ABA, Hu J (2014) Time of emergence for regional sea-level change. Nat Clim Change 4:10061010. doi:10.1038/nclimate2397

McGregor S, Sen Gupta A (2012) Constraining wind stress products with sea surface height observations and implications for Pacific ocean sea level trend attribution. J Clim 25:81648176

Meehl GA, Stocker TF, Collins WD, Friedlingstein P, Gaye AT, Gregory JM, Kitoh A, Knutti R, Murphy JM, Noda A, Raper SCB, Watterson IG, Weaver AJ, Zhao Z (2007) Global climate projections. In: Solomon S, Qin D, Manning M, Chen Z, Marquis M, Averyt KB, Tignor M, Miller HL (eds) Climate change 2007: the physical science basis. Contribution of working group I to the fourth assessment report of the intergovernmental panel on climate change. Cambridge University Press, Cambridge

Meehl GA, Hu A, AJ M, Fasullo JY, Trenberth KE (2013) Externally forced and internally generated decadal climate variability associated with the interdecadal Pacific Oscillation. J Clim 26:7298-7310

Merrield MA, Maltrud ME (2011) Regional sea level trends due to a Pacific trade wind intensification. Geophys Res Lett 38:L21605. doi:10.1029/2011GL049576
Merrifield M (2013) A shift in western tropical Pacific sea level trends during the 1990s. J Clim 24:41264138

Merrifield M, Thompson P, Lander M (2011) Multidecadal sea level anomalies and trends in the western tropical Pacific. Geophys Res Lett 39:L13602

Meyssignac B, Salas y Mélia D, Becker DM, Llovel W, Cazenave A (2012) Tropical Pacific spatial trend patterns in observed sea level: internal variability and/or anthropogenic signature? Clim Past 8:787-802. doi:10.5194/cp-8-787-2012

Mitchell JFB, Johns TC, Eagles M, Ingram WJ, Davis RA (1999) Towards the construction of climate change scenarios. Clim Change 41:547-581

Mitchell TD (2003) Pattern scaling: an examination of the accuracy of the technique for describing future climates. Clim Change 60:217-242

Mitrovica JX, Tamisiea ME, Davis JL, Milne GA (2001) Recent mass balance of polar ice sheets inferred from patterns of global sealevel change. Nature 409:1026-1029

Nicholls RJ, Marinova N, Lowe JA, Brown S, Vellinga P, de Gusmo D, Hinkel J, To RSJ (2011) Sea-level rise and its possible impacts given a beyond $4^{\circ} \mathrm{C}$ world in the twenty-first century. Philos Trans R Soc A 369:161181

Palmer MD, Haines K, Ansell TJ, Tett SFB (2007) Isolating the signal of ocean global warming. Geophys Res Lett. doi:10.1029/20 07GL031712

Pardaens AK, Gregory JM, Lowe JA (2011) A model study of factors influencing projected changes in regional sea level over the 21st century. Clim Dyn 36:2015-2033. doi:10.1007/ s00382-009-0738-x

Peltier WR (2004) Global glacial isostasy and the surface of the Ice-Age Earth: the ICE-5G (VM2) model and GRACE. Ann Rev Earth and Planet Sci 32:111-149. doi:10.1146/annurev. earth.32.082503.144359

Perrette M, Landerer FW, Riva R, Frieler K, Meinshausen M (2013) A scaling approach to project regional sea level rise and its uncertainties. Earth Syst Dyn 4:11-29

Ray RD, Douglas BC (2011) Experiments in reconstructing twentieth-century sea levels. Prog Oceanogr 91:496-515. doi:10.1016/j. pocean.2011.07.021

Rhein M, Rintoula S, Aoki S, Campos E, Chambers D, Feely R, Gulev S, Johnson G, Josey S, Kostianoy A, Mauritzen C, Roemmich D, Talley L, Wang F (2013) Observations: ocean. In: Stocker TF, Qin D, Plattner GK, Tignor M, Allen SK, Boschung J, Nauels A, Xia Y, Bex V, Midgley PM (eds) Climate change 2013: the physical science basis. Contribution of working group I to the fifth assessment report of the intergovernmental panel on climate change. Cambridge University Press, Cambridge

Santer BD, Wigley TML, Schlesinger ME, Mitchell JFB (1990) Developing climate scenarios from equilibrium GCM results. Tech Rep 47, MPI Hamburg

Sen Gupta A, Jourdain NC, Brown JN, Monselesan D (2013) Climate drift in the CMIP5 models. J Clim 26:8597-8615. doi:10.1175/ JCLI-D-12-00521.1

Slangen A, Carson M, Katsman C, van de Wal RK, Stammer D (2014) Projecting twenty-first century regional sea-level changes. Clim Change 124:317332. doi:10.1007/s10584-014-1080-9

Slangen ABA, Katsman CA, van de Wal RSW, Vermeersen LLA, Riva REM (2012) Towards regional projections of twenty-first century sea-level change based on IPCC SRES scenarios. Clim Dyn 38:1191-1209. doi:10.1007/s00382-011-1057-6

Tamisiea ME (2011) Ongoing glacial isostatic contributions to observations of sea level change. Geophys J Int 186:10361044

Taylor KE, Stouffer RJ, Meehl GA (2012) An Overview of CMIP5 and the experiment design. Bull Am Meteorol Soc 93:485-498. doi:10.1175/BAMS-D-11-00094.1 
Thompson DWJ, Wallace JM, Hegerl GC (2000) Annular modes in the extratropical circulation. Part II: Trends. J Clim 13(5):1018-1036

Timmermann A, McGregor S, Jin FF (2011) Wind effects on past and future regional sea level trends in the Southern Indo-Pacific. J Clim 23:4429-4437
Winton M, Takahashi K, Held IM (2010) Importance of ocean heat uptake efficacy to transient climate change. J Clim 23:23332344. doi:10.1175/2009JCLI3139.1

Yin J (2012) Century to multi-century sea level rise projections from CMIP5 models. Geophys Res Lett 39:17. doi:10.1029/201 2GL052947 